\title{
molecules
}

ISSN 1420-3049

www.mdpi.com/journal/molecules

Review

\section{New Advances in Titanium-Mediated Free Radical Reactions}

\author{
Bianca Rossi ${ }^{1}$, Simona Prosperini ${ }^{1,2}$, Nadia Pastori ${ }^{1}$, Angelo Clerici ${ }^{1}$ and Carlo Punta ${ }^{1,2, *}$
}

1 Department of Chemistry, Materials, and Chemical Engineering "Giulio Natta", Politecnico di Milano, P.zza Leonardo da Vinci 32, 20133 Milano, Italy;

E-Mails: brossi@chem.polimi.it (B.R.); simona.prosperini@chem.polimi.it (S.P.); nadia.pastori@polimi.it (N.P.); angelo.clerici@polimi.it (A.C.)

2 INSTM (National Consortium for Materials Science and Technology) Local Unit, Politecnico di Milano, 20133 Milan, Italy

* Author to whom correspondence should be addressed; E-Mail: carlo.punta@polimi.it; Tel.: +39-022-399-3026; Fax: +39-022-399-3180.

Received: 31 October 2012; in revised form: 28 November 2012 / Accepted: 6 December 2012 / Published: 11 December 2012

\begin{abstract}
Titanium complexes have been widely used as catalysts for $\mathrm{C}-\mathrm{C}$ bond-forming processes via free-radical routes. Herein we provide an overview of some of the most significant contributions in the field, that covers the last decade, emphasizing the key role played by titanium salts in the promotion of selective reactions aimed at the synthesis of multifunctional organic compounds, including nucleophilic radical additions to imines, pinacol and coupling reactions, ring opening of epoxides and living polymerization.
\end{abstract}

Keywords: radical chemistry; titanium; titanocene; $\mathrm{TiCl}_{3} ; \mathrm{TiCl}_{4}$; nucleophilic addition; pinacolization; cross-coupling; ring opening of epoxides; multicomponent reactions

\section{Introduction}

Since the pioneering work of Barton et al. [1] of 1960, the potential of radical reactions has been extensively explored, thanks also to the growth of advanced techniques for the detection of radicals and the definition of their structure and reactivity. This ongoing research has allowed the development of innovative selective free-radical reactions, occurring under mild conditions and tolerated by common functional groups, making such processes suitable for the synthesis and functionalization of organic compounds [2,3]. In the last decade, important improvements in this filed have been achieved 
by combining radical chemistry with transition-metal catalysis, due to the key role of transition metal complexes both in promoting and highly controlling sophisticated free-radical synthetic routes [4-7]. This approach has been adopted for different applications, ranging from oxidative [8-10] and reductive [11] radical processes to the selective $\mathrm{C}-\mathrm{C}$ and $\mathrm{C}-\mathrm{N}$ bond formation [12-19], passing through living polymerization [20-22].

Among the transition metals widely employed for these purposes, in the present review we focus on titanium and address the recent advances in selective free-radical processes mediated by $\mathrm{Ti}$ (III) and Ti(IV) complexes. Titanium, the seventh most abundant metal on Earth, is one of the cheapest transition metals and a lot of titanium compounds are nontoxic and environmentally friendly. The high added value of using titanium salts to promote radical synthetic routes not only relies on their selective intervention in the initiation and the termination steps of the radical chain, but also on their remarkable coordinating role shown, due to their Lewis acid character.

Limiting our overview to the results reported in the literature in the past twelve years, Section 2 describes the potential of $\mathrm{Ti}(\mathrm{III}) / \mathrm{PhN}_{2}{ }^{+}$and $\mathrm{Ti}(\mathrm{III}) /$ hydroperoxide systems in promoting one-pot, multicomponent, nucleophilic radical additions to aldimines and ketimines generated in situ. Section 3 deals with the most significant examples achieved in pinacol and coupling reactions while, in Section 4, ample discussion is devoted to the ring-opening of epoxides mediated and catalyzed by titanocenes. Finally, in Section 5, we briefly disclose the recent results reported in the field of living polymerization.

It is noteworthy that titanium dioxide is also able to promote free-radical processes by photoactivation at suitable wavelengths, but this chemistry is not the object of the present review. The combined action of light and $\mathrm{TiO}_{2}$, under oxidative conditions, finds interesting applications in the field of pollutant photodegradation, selective organic photosynthesis and antibacterial activity. For a comprehensive overview on the $\mathrm{TiO}_{2}$ photocatalytic activity, we refer the reader to some very recent reviews [23-26].

\section{Nucleophilic Radical Addition to Imines}

Nucleophilic radical addition to imines, iminium salts or hydrazones, mediated by transition metal salts such as manganese [27], copper [28-30], and zirconium [31-33], represents a valuable alternative to the classical ionic routes for the selective $\mathrm{C}-\mathrm{C}$ bond formation and the synthesis of high added value polifunctional molecules [12-17]. This approach becomes even more intriguing if the transition metal is able to promote, in one-pot, the in situ formation of the imine followed by nucleophilic addition, in accordance with the multicomponent reaction (MCR) strategy. In the last decade $\mathrm{TiCl}_{3}$, because of this particular specificity, has attracted the increasing interest of our research group, enabling us to develop quite a number of free-radical MCRs.

\section{1. $\mathrm{TiCl}_{3} / \mathrm{ArN}_{2}^{+}$System}

The selective arylative amination of aromatic aldehydes using the $\mathrm{TiCl}_{3} / \mathrm{ArN}_{2}{ }^{+}$system (Scheme 1) was first reported by Clerici and Porta in 1990 [34]. According to this procedure, Ti(III) promotes the aryldiazonium salt decomposition to an aryl radical. Simultaneously, the Ti(IV) formed, due to its oxophilicity, favors the in situ formation of aldimines from anilines and aldehydes. Furthermore, as a 
strong Lewis acid, $\mathrm{Ti}(\mathrm{IV})$ enhances, via $\mathrm{N}$-complexation, the electrophilicity of the $\mathrm{C}=\mathrm{N}$ bond carbon atom towards nucleophilic attack by the aryl radical.

Scheme 1. Arylative amination of aldehydes promoted by the $\mathrm{TiCl}_{3} / \mathrm{ArN}_{2}{ }^{+}$system.

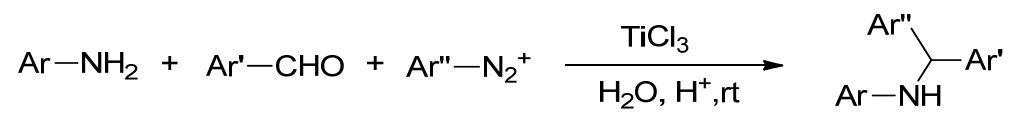

This reaction occurs in an aqueous environment, where it is well known that imines, easily hydrolysable, are quite unstable and less prone to a nucleophilic attack. Later, in 2005, this approach was successfully extended to a wider range of nucleophilic radical sources by introducing a fourth component in the cascade reaction. In fact, in the presence of alkyl iodides [35], the phenyl radical, deriving from the corresponding diazonium salt decomposition, promotes the fast iodide-atom abstraction, generating an alkyl radical which, in turn, undergoes a nucleophilic attack onto aldimines generated in situ (Scheme 2).

Scheme 2. Nucleophilic radical addition to aldimines promoted by the $\mathrm{TiCl}_{3} / \mathrm{PhN}_{2}{ }^{+}$system.

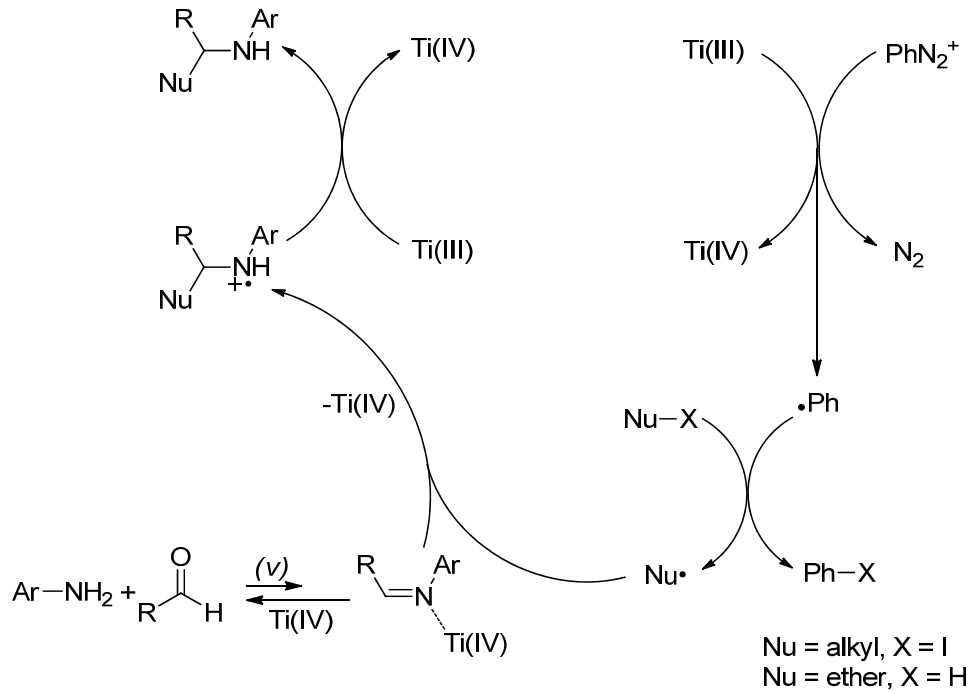

According to a similar procedure, the nucleophilic addition of ethers onto aldimines was performed via $\alpha-\mathrm{H}$ atom abstraction via the same phenyl radical source (Scheme 2) [36], providing the first radical version of the Mannich reaction. The resulting iminium radical is then reduced by a second equivalent of $\mathrm{TiCl}_{3}$, rendering the overall mechanism irreversible towards the formation of the desired product.

\section{2. $\mathrm{TiCl}_{3} / \mathrm{ROOH}_{\text {and }} \mathrm{TiCl}_{4}-\mathrm{Zn} / \mathrm{ROOH}$ Systems}

In 2006, we reported a series of new one-pot multicomponent reactions mediated by $\mathrm{TiCl}_{3}$ or $\mathrm{TiCl}_{4}-\mathrm{Zn}$ hydroperoxide systems, which overcome some limits of the previously disclosed approach. The choice of the right hydroperoxide allows the formation of more practical, efficient and selective precursors of the radical cascade. As a consequence, the new procedure can be extended to a wider range of nucleophilic sources and can be applied even onto ketimines generated in situ, allowing us to create different building blocks for bioactive molecules (Scheme 3). Moreover, this reaction occurs 
under mild conditions in 30-60 min. Finally, the proposed approach requires neither the pre-formation of the imine nor the protection of the amino group and may easily be conducted under aqueous conditions.

Scheme 3. Radical addition to imines triggered by $\mathrm{TiCl}_{3}$ or $\mathrm{TiCl}_{4}-\mathrm{Zn} / \mathrm{ROOH}$ systems.

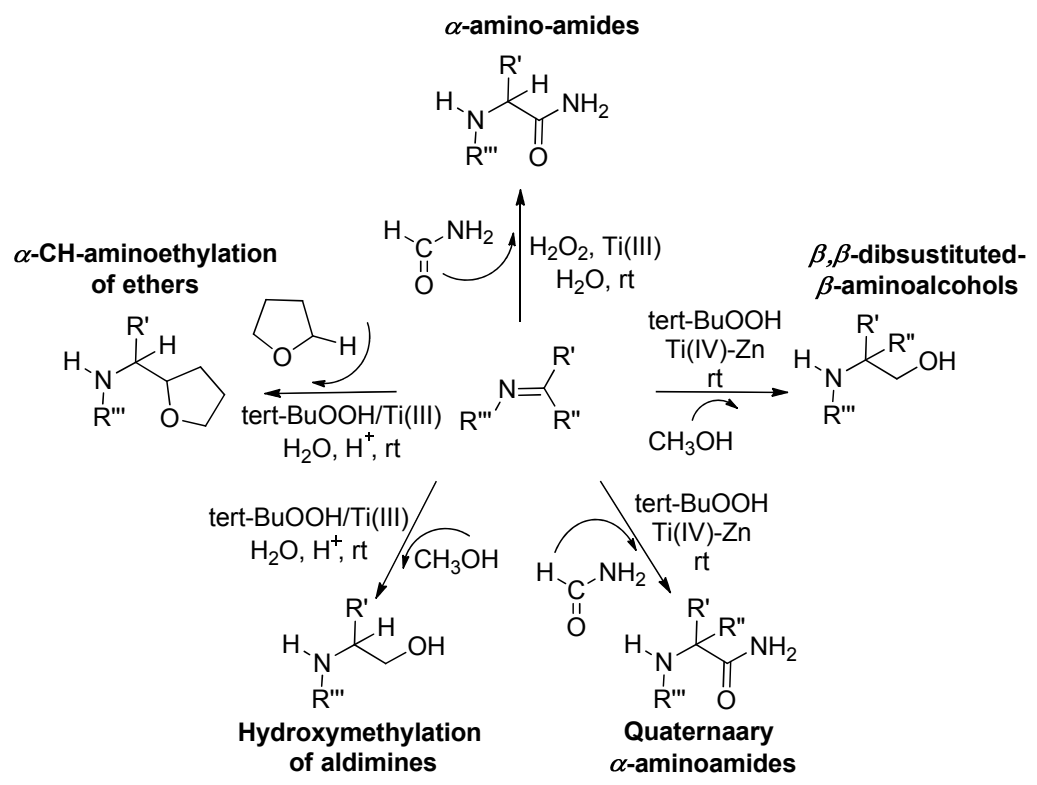

\subsection{1. $\mathrm{TiCl}_{3} / \mathrm{ROOH}$}

An alternative route to the radical aminoalkylation of ethers was proposed by Porta and co-workers in 2006 [37]. The $\mathrm{TiCl}_{3}$-tert-butylhydroperoxide $(t-\mathrm{BuOOH})$ system was revealed to be a more practical, efficient and selective precursor of $\alpha$-alkoxyalkyl radicals from ethers. Accordingly, $\mathrm{TiCl}_{3} / t$ - $\mathrm{BuOOH}$ readily assemble an aniline, an aldehyde, and an ether, leading to 1,2-aminoethers (Scheme 4).

Scheme 4. Aminoalkylation of ethers promoted by the $\mathrm{TiCl}_{3} / \mathrm{t}-\mathrm{BuOOH}$ system.

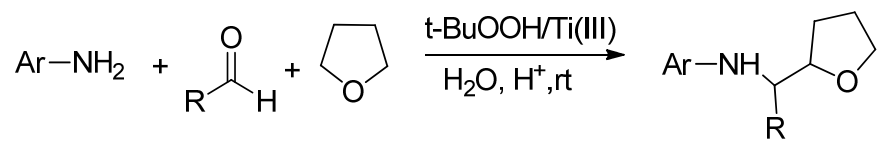

In agreement with the general proposed mechanism (Scheme 5), the dropwise addition of $\mathrm{TiCl}_{3}$ into the reaction medium promotes the decomposition of the hydroperoxide, leading to the formation of tert-butoxyl radical ( $t$-BuO-). The latter undergoes an $\alpha-\mathrm{H}$ abstraction from the ether, with higher selectivity with respect to the phenyl radical generated by the $\mathrm{TiCl}_{3} / \mathrm{PhN}_{2}{ }^{+}$system (no $\beta$-hydrogen abstraction was observed). Once formed, the nucleophilic ketyl radical adds to the aldimine generated in situ, in analogy with the mechanism indicated in Scheme 2. 
Scheme 5. Nucleophilic radical generation promoted by the $\mathrm{TiCl}_{3} / \mathrm{t}-\mathrm{BuOOH}$ system .

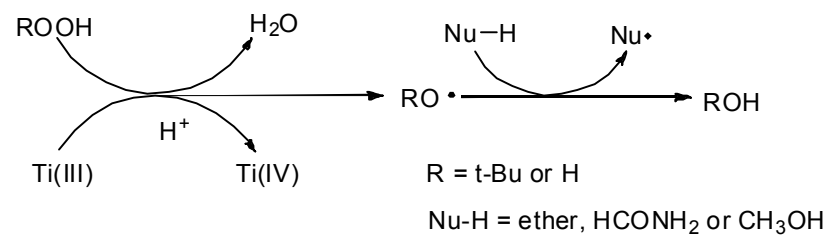

The reaction goes like a titration and can be easily monitored by considering the different color of the species involved: $\mathrm{Ti}$ (III) (violet) and $\mathrm{Ti}(\mathrm{IV})$ (orange). Thus, the addition of the $\mathrm{TiCl}_{3}$ solution stops when a pale blue color is barely maintained to ensure the complete decomposition of the peroxide. This methodology was then extended to the selective carbamoylation of aldimines in formamide [38], providing a radical version of the Strecker synthesis of $\alpha$-amino amides (Scheme 6a), and to the aminoalkylation of methanol [39], leading to the formation of $\alpha, \beta$-amino alcohols (Scheme 6b).

Scheme 6. (a) Carbamoylation of aldimines. (b) Hydroxymethylation of aldimines.

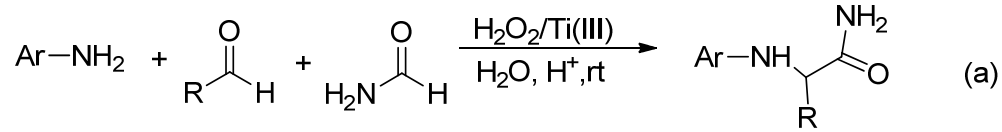

$$
\begin{aligned}
& \mathrm{Ar}-\mathrm{NH}_{2}+\underset{\mathrm{R}}{\stackrel{\mathrm{O}}{\mathrm{H}}+\mathrm{CH}}+\mathrm{CH}_{3} \mathrm{OH} \underset{\mathrm{H}_{2} \mathrm{O}, \mathrm{H}^{+}, \mathrm{rt}}{\stackrel{\mathrm{t}-\mathrm{BuOOH} / \mathrm{T}(\mathrm{III})}{\longrightarrow}} \mathrm{Ar}-\mathrm{NH}_{\mathrm{R}} \mathrm{OH} \text { (b) }
\end{aligned}
$$

When the same protocol is used in the presence of an alcoholic solvent different from methanol, a domino reaction competes with the one-pot process (Scheme 7) [40].

Scheme 7. Domino reaction in alcoholic solvent promoted by the $\mathrm{TiCl}_{3} / \mathrm{t}-\mathrm{BuOOH}$ system.

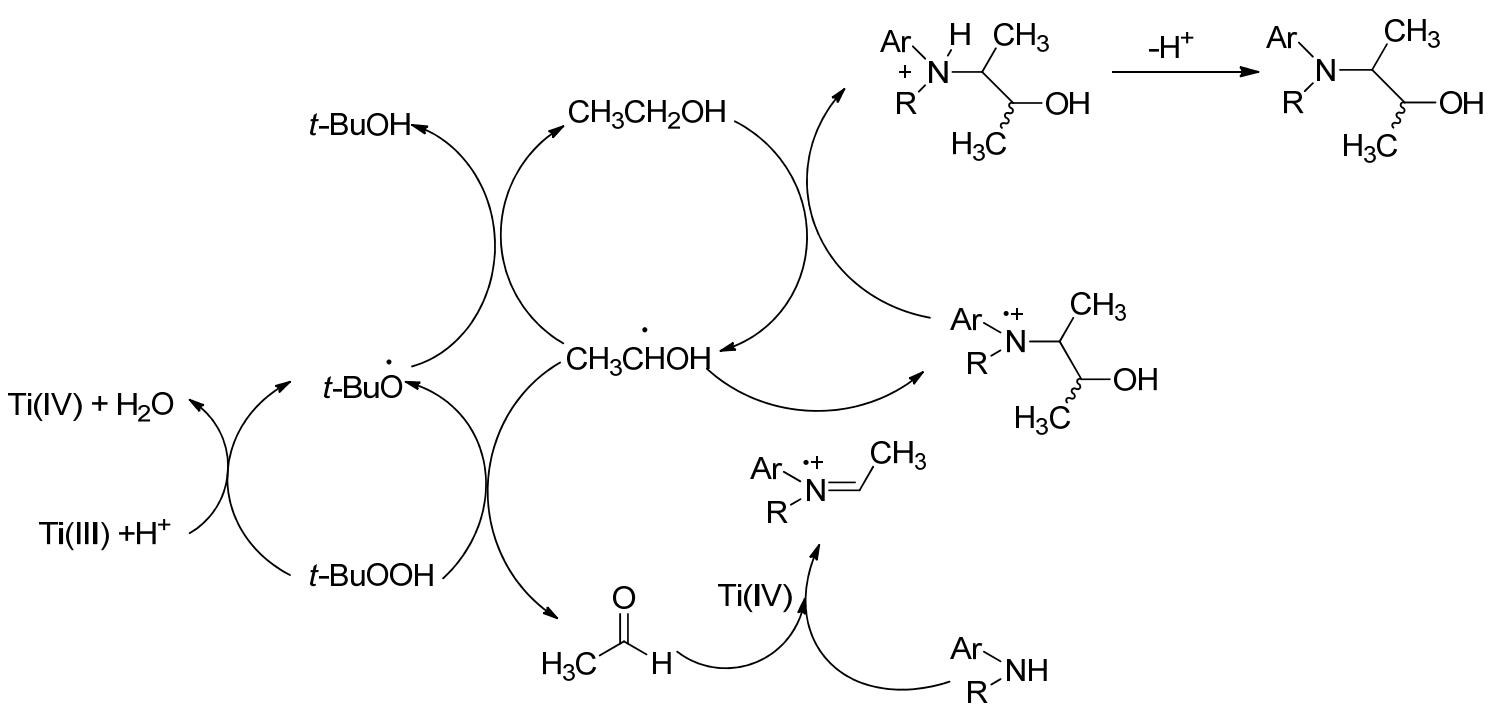

In fact, in this case the ketyl radical formed behaves as a strong reducing agent [41] and competes with $\mathrm{Ti}(\mathrm{III})$ in the reduction of $t-\mathrm{BuOOH}$, leading to the formation of the corresponding aldehyde. The latter, when in the presence of an aniline, promotes the formation of an aldimine, which is prone to 
nucleophilic attack by a second ketyl radical. As a consequence, when the reaction is carried out in the absence of aldehydes, it proceeds to the formation of $\beta$-amino alcohols by in situ generation of an aldehyde.

\subsection{2. $\mathrm{TiCl}_{4}-\mathrm{Zn} / \mathrm{ROOH}$}

Since ketimines are less stable in aqueous medium and less reactive than aldimines, studies involving the reductive radical addition to ketimines are scant in comparison with those conducted on their aldimine counterparts. Moreover, in almost all cases the preformation of ketimines is required. It is because of this low stability under non-anhydrous conditions that the $\mathrm{TiCl}_{3} / \mathrm{ROOH}$ system resulted ineffective when an aniline, a ketone and formamide were assembled in one-pot with the intention of promoting the formation of quaternary $\alpha$-amino amides. Nevertheless, we recently reported an optimization of the previously discussed protocol, consisting in the replacement of the aqueous $\mathrm{TiCl}_{3}$ with an anhydrous solution of $\mathrm{TiCl}_{4}$ in $\mathrm{CH}_{2} \mathrm{Cl}_{2}$ in combination with $\mathrm{Zn}$ powder (Scheme 8a) [42]. The same protocol was successfully applied in methanol solvent for the selective hydroxymetylation of ketimines, affording the corresponding $\beta$, $\beta$-disubstituted- $\beta$-amino alcohols (Scheme $8 \mathrm{~b}$ ) [43].

Scheme 8. (a) Carbamoylation of ketimines. (b) Hydroxymethylation of ketimines.

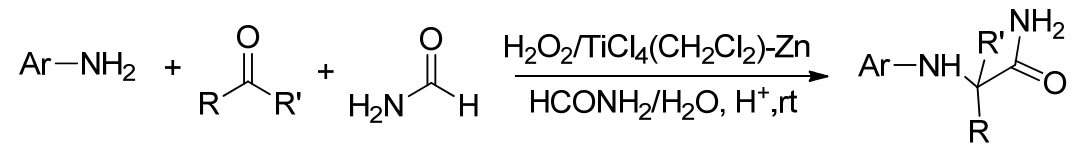

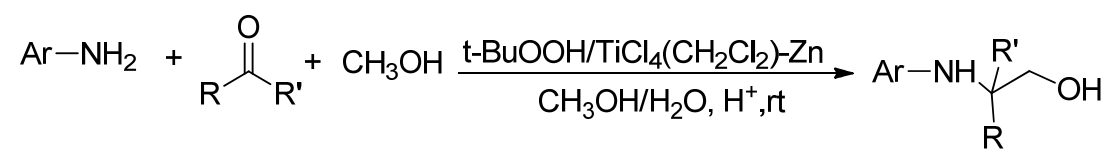

The mechanism is analogous to that previously discussed and $\mathrm{Zn}$ metal has the unique role of sacrificial reductant for the in situ generation of Ti(III) from Ti(IV) (Scheme 9).

Scheme 9. Nucleophilic addition to ketimines promoted by the $\mathrm{TiCl}_{4}-\mathrm{Zn} / \mathrm{ROOH}$ system.

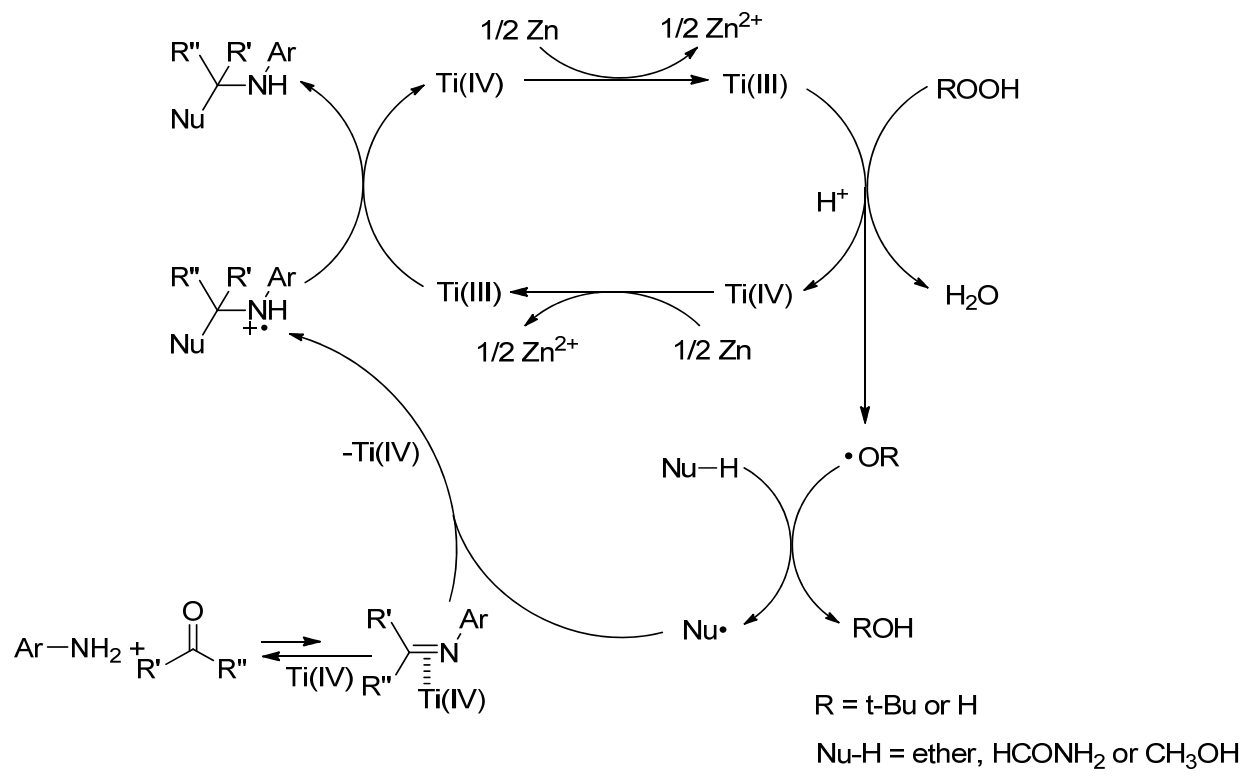


Surprisingly, the $\mathrm{TiCl}_{4}-\mathrm{Zn} / \mathrm{t}-\mathrm{BuOOH}$ combination was also revealed to be even more effective and selective with respect to the $\mathrm{TiCl}_{3} / t$ - $\mathrm{BuOOH}$ approach in promoting domino reactions. 1,2-Amino alcohols were obtained in high yields by simply combining two molecules of ethanol or propanol in the presence of aromatic and aliphatic amines, without requiring the addition of aldehydes or ketones (Scheme 10) [44]. Even more interesting is that an analogous reaction occurred by operating in cyclic ether solvents [44].

Scheme 10. Domino reaction in alcohols promoted by the $\mathrm{TiCl}_{4}-\mathrm{Zn} / \mathrm{ROOH}$ system.

$$
\begin{aligned}
& \stackrel{\mathrm{R}^{\prime}}{\mathrm{R}^{\prime}} \mathrm{NH}+2 \mathrm{R}^{\prime \prime} \mathrm{CH}_{2} \mathrm{OH} \frac{\mathrm{t}-\mathrm{BuOOH} / \mathrm{Ti}(\mathrm{IV})-\mathrm{Zn}}{\mathrm{H}_{2} \mathrm{O}, \mathrm{H}^{+}, \mathrm{rt}} \\
& \mathrm{R}=\text { Alkyl, Aryl } \\
& \mathrm{R}^{\prime}=\mathrm{H}, \mathrm{Me} \\
& \mathrm{R}^{\prime}=\mathrm{H}, \mathrm{Me}, \mathrm{Et}, \mathrm{n}-\mathrm{Pr}
\end{aligned}
$$

According to the proposed mechanism (Scheme 11), it was possible to synthetize amino alcohols by electrophilic amination of ketyl radicals, promoting the formation of the imine via ring opening of the ether cyclic and the subsequent nucleophilic radical addition by a second ketyl radical.

Scheme 11. Domino reaction in cyclic ethers promoted by the $\mathrm{TiCl}_{4}-\mathrm{Zn} / \mathrm{ROOH}$ system.

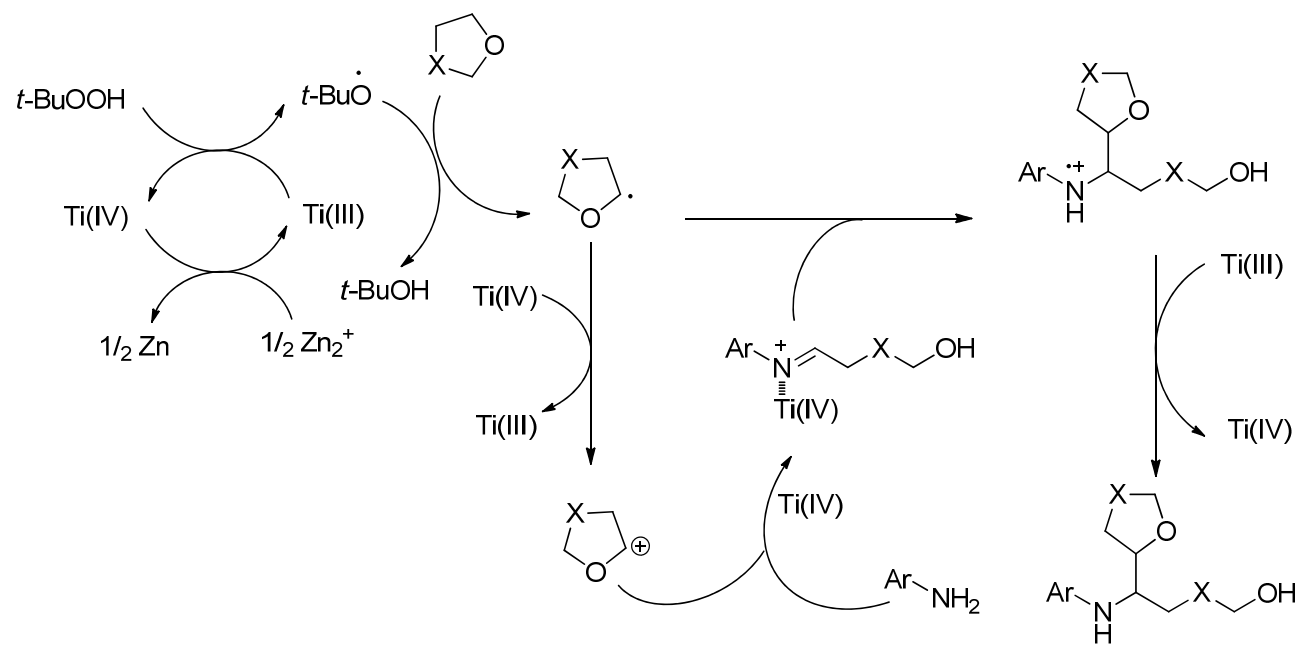

\section{3. $\mathrm{Cp}_{2} \mathrm{TiCl}_{2} / \mathrm{Zn}$ Systems}

In 2011, Saha and Roy reported a selective radical-induced allylation of pre-formed aldimines for the synthesis of homoallyl amines [45]. The combination of titanocene(IV) dichloride and $\mathrm{Zn}$ dust in THF under argon leads to the formation of $\mathrm{Cp}_{2} \mathrm{TiCl}$ in situ. The latter acts as radical initiator, promoting the formation of the allyl radical from the corresponding allyl bromide (Scheme 12). This approach was successfully applied to the synthesis of deoxy aza-disaccharides and for the preparation of the bicyclic skeleton of alkaloids. 
Scheme 12. $\mathrm{Cp}_{2}$ TiCl-mediated allylation of aromatic aldimines.<smiles>C=CCC(Nc1ccccc1)c1ccccc1</smiles>

\section{Coupling Reactions}

Radical coupling mediated by transition metal salts represents one of the pillars of free-radical synthesis. Once again, simple titanium salts and titanium complexes bearing specific organic ligands result particularly effective in promoting intramolecular as well as intermolecular coupling with high stereo-, diastero- and even enantioselectivity [46,47]. Among the several protocols developed, pinacolization, allylation and cross-coupling reactions have attracted particular attention in the last decade.

\subsection{Pinacol Reactions}

The pinacolization of aldehydes is one of the most studied reactions in the area of radical coupling for $\mathrm{C}-\mathrm{C}$ bond formation. This interest arises from the usefulness of hydrobenzoins as chiral auxiliaries and ligands for stereoselective organic synthesis. Moreover, the pinacol reaction represents an ideal tool for studying the enatioselective catalyzed formation of radicals [48].

This reaction can be accomplished with a variety of one- or two-electron metal reducing agents. Our group has widely investigated the role that $\mathrm{TiCl}_{3}$ and $\mathrm{TiCl}_{4}$ play in promoting pinacolization of aromatic aldehydes. In particular, a $d l$-stereodirecting pinacolization was accomplished by using $\mathrm{TiCl}_{3}$ in a strictly anhydrous non-coordinating solvent $\left(\mathrm{CH}_{2} \mathrm{Cl}_{2}\right)$, favored by $\mathrm{Ti}(\mathrm{III})$-complexation of the oxygen atom of the carbonyl group, which lowers the reduction potential of the aromatic aldehyde (Scheme 13) [49].

Scheme 13. $d l$-Stereodirecting pinacolization of aromatic aldehydes promoted by $\mathrm{TiCl}_{3}$.

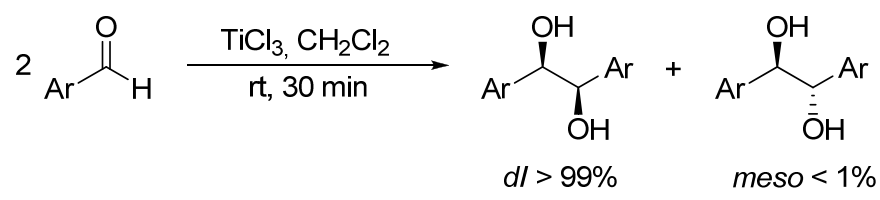

Later on, in the same $\mathrm{CH}_{2} \mathrm{Cl}_{2}$ solvent, an analogous reactivity was observed when $\mathrm{TiCl}_{4}$ is coupled with diisopropylethylamine (DIPEA). Porta and co-workers [50] revealed how, in this case, the $\mathrm{TiCl}_{4} / \mathrm{DIPEA}$ complexation is the driving force of the overall process, causing the instantaneous formation of Ti(III) by an inner-sphere electron transfer from Ti(IV) to DIPEA. Once generated, Ti(III) coordinates the carbonyl oxygen of an added aromatic aldehyde, promoting its reductive dimerization.

More recently we have unexpectedly found that, despite the non-anhydrous conditions, the aqueous $\mathrm{TiCl}_{3} / t$-BuOOH redox system promotes the hydrodimerization of aromatic aldehydes, when used in combination with an alcoholic co-solvent like ethanol [41].

In accordance with the proposed mechanism (Scheme 14), the explanation of the paradox relies in the reducing power of the $\alpha$-hydroxyalkyl radicals generated in situ via $\mathrm{H}$-atom abstraction from the 
alcoholic solvent by tert-butoxy radical. These ketyl radicals, instead of $\mathrm{Ti}(\mathrm{III})$, are the actual reductants of the aromatic aldehydes.

Scheme 14. Proposed mechanism for the $\mathrm{TiCl}_{3} / t-\mathrm{BuOOH}$ mediated pinacolization.

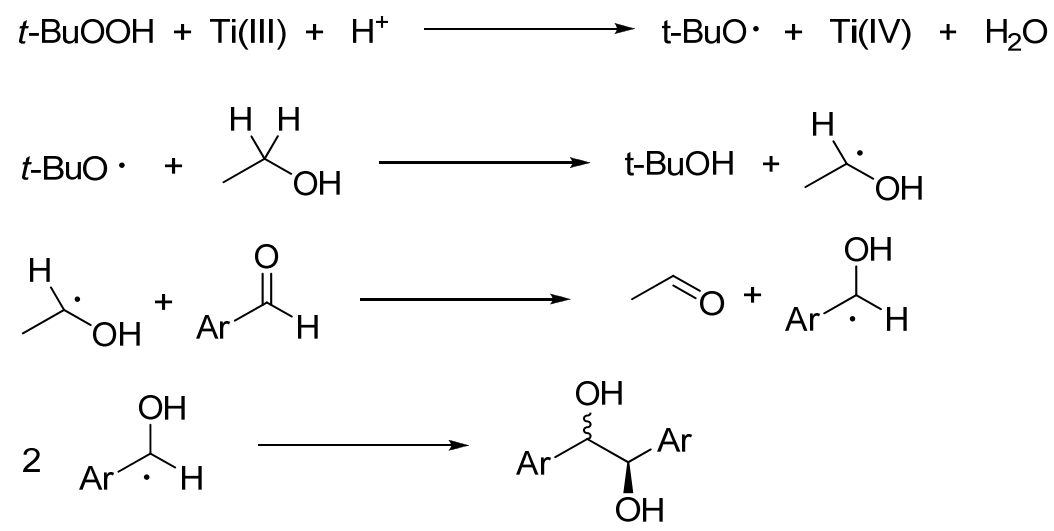

Pinacolization of aromatic ketones like acetophenone can be performed in good yields and high stereoselectivity $(d l /$ meso ratio $=9 / 1)$ in the presence of $\mathrm{Cp}_{2} \mathrm{TiCl}$, generated in situ by combining $\mathrm{Cp}_{2} \mathrm{TiCl}_{2}$ with an excess of Mn dust [51].

Moreover, new families of Ti(IV) complexes bearing chiral ligands (1, $\mathbf{2}$ and 3, Figure 1) have been developed in the last decade. These derivatives, when employed in combination with co-reducing agents, revealed to be ideal precursors of chiral $\mathrm{Ti}$ (III) catalysts for the enantioselective pinacol coupling of aldehydes.

Figure 1. Chiral Ti(IV) complexes.

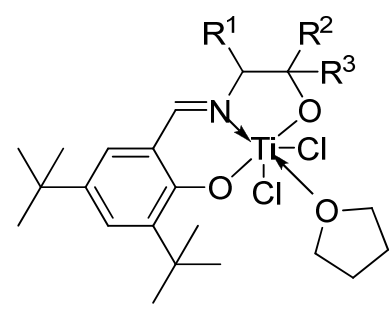

1

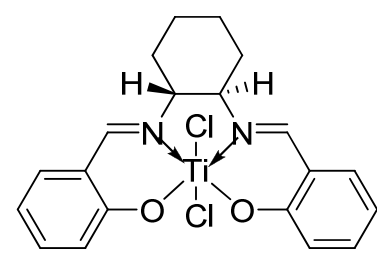

2

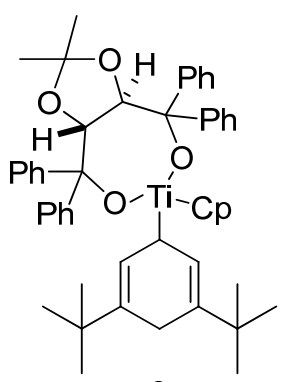

3

In 2001 Riant and co-workers [52] reported the combined use of stoichiometric amounts of the titanium-Schiff base complex 1 and $\mathrm{Mn}$ to promote the asymmetric $d l$-diastereoselective pinacolization with high yields and enantioselectivity up to $91 \%$ (Scheme 15).

Scheme 15. Riant's pinacolization mediated by stoichiometric amounts of complex 1.<smiles>[2H]C=C[14CH3]</smiles><smiles>OC(Br)[C@@H](O)[18OH]</smiles> 
An analogous result was achieved by Joshi et al., who succeeded in performing a catalytic cycle in $\mathrm{CH}_{3} \mathrm{CN}$ with $10 \mathrm{~mol} \%$ concentration of complex 2 and stoichiometric amounts of $\mathrm{Me}_{3} \mathrm{SiCl}$ (TMSCl), followed by the addition of tetrabutylammonium fluoride in THF (Scheme 16) [53].

Scheme 16. Pinacolization mediated by catalytic amounts of complex 2.

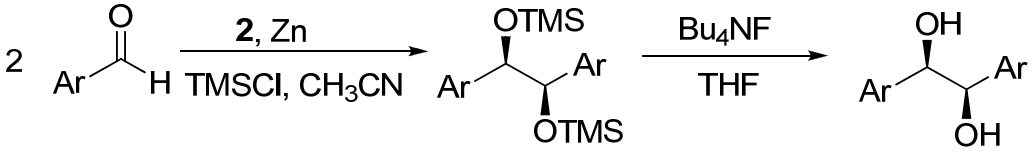

In 2005, Knoop and Studer reported a new method for the in situ generation of Ti(III) complexes without requiring a co-reducing reagent [54]. Cyclohexadienyl-Ti(IV) compounds, prepared from the corresponding lithiated cyclohexadienes, led to the corresponding Ti(III) complexes upon thermal C-Ti bond homolysis (Scheme 17). Following this procedure, complex 3 was readily prepared and employed to perform pinacol coupling of aromatic aldehydes with diastereomeric and enantiomeric excess.

Scheme 17. Pinacolization of aromatic aldehydes promoted by 3 .

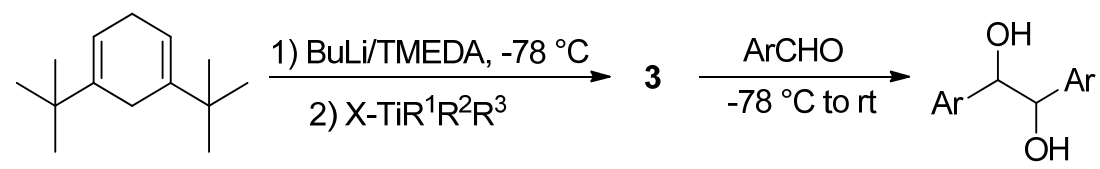

\subsection{Allylation Reactions}

Among radical coupling reactions, the Barbier-type allylation of carbonyl derivatives, mediated by different transition metals, has attracted particular attention due to its considerable synthetic relevance (Scheme 18). The generic strategy for this process consists in the transformation of allyl halides into the corresponding allyl radicals which, in turn, would add onto the carbonyl compounds present in the reaction medium.

Scheme 18. Barbier-type allylation of carbonyl derivatives.

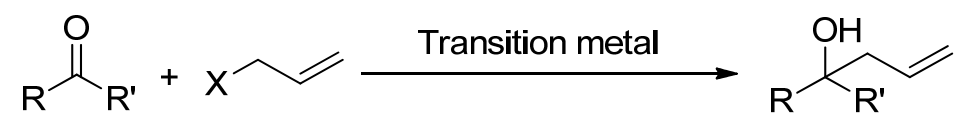

Very recently, Justicia et al. have shown that an excess of titanocene(III) chloride, generated in situ by the $\mathrm{Cp}_{2} \mathrm{TiCl}_{2} / \mathrm{Mn}$-dust system, allows to extend this protocol to the crotylation of carbonyl compounds [55].

However, most of the reported protocols usually require stoichiometric amounts of these metals, which is detrimental for the sustainability of the process. Stoichiometric quantities are generally necessary even when operating in the presence of $\mathrm{Ti}$ complexes, limiting the applicability of this approach to enatioselective additions [46]. In this context, in 2009 a comprehensive contribution by Oltra and co-workers has shown how catalytic proportions of titanocene(III) complexes, when combined with the regenerating agent 4 (obtained by mixing $\mathrm{TMSCl}$ and 2,4,6-collidine), are able to promote the Barbier-type allylation, in accordance with the mechanism reported in (Scheme 19) [56]. 
Scheme 19. Barbier-type allylation mechanism promoted by catalytic titanocene.

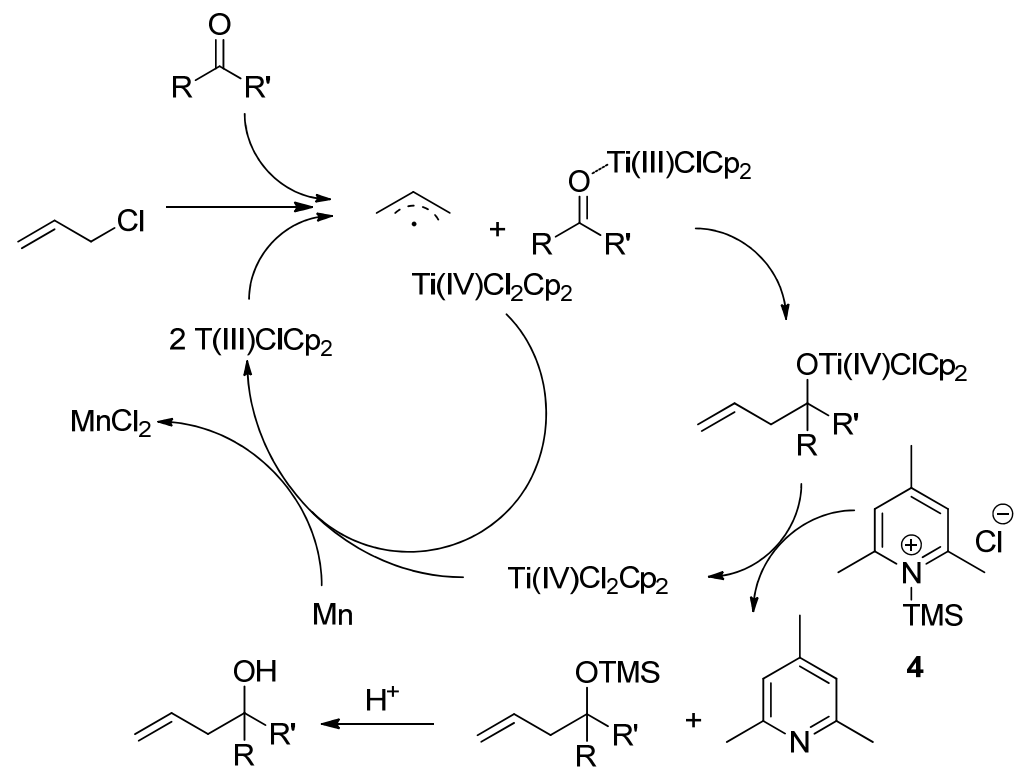

This approach has been successfully applied for the allyl radical addition onto aldehydes and ketones (including functionalized carbonyl substrates), for cyclization reactions and for prenylation of aldehdyes (Scheme 20).

Scheme 20. Examples of Barbier-type allylations promoted by catalytic titanocene.

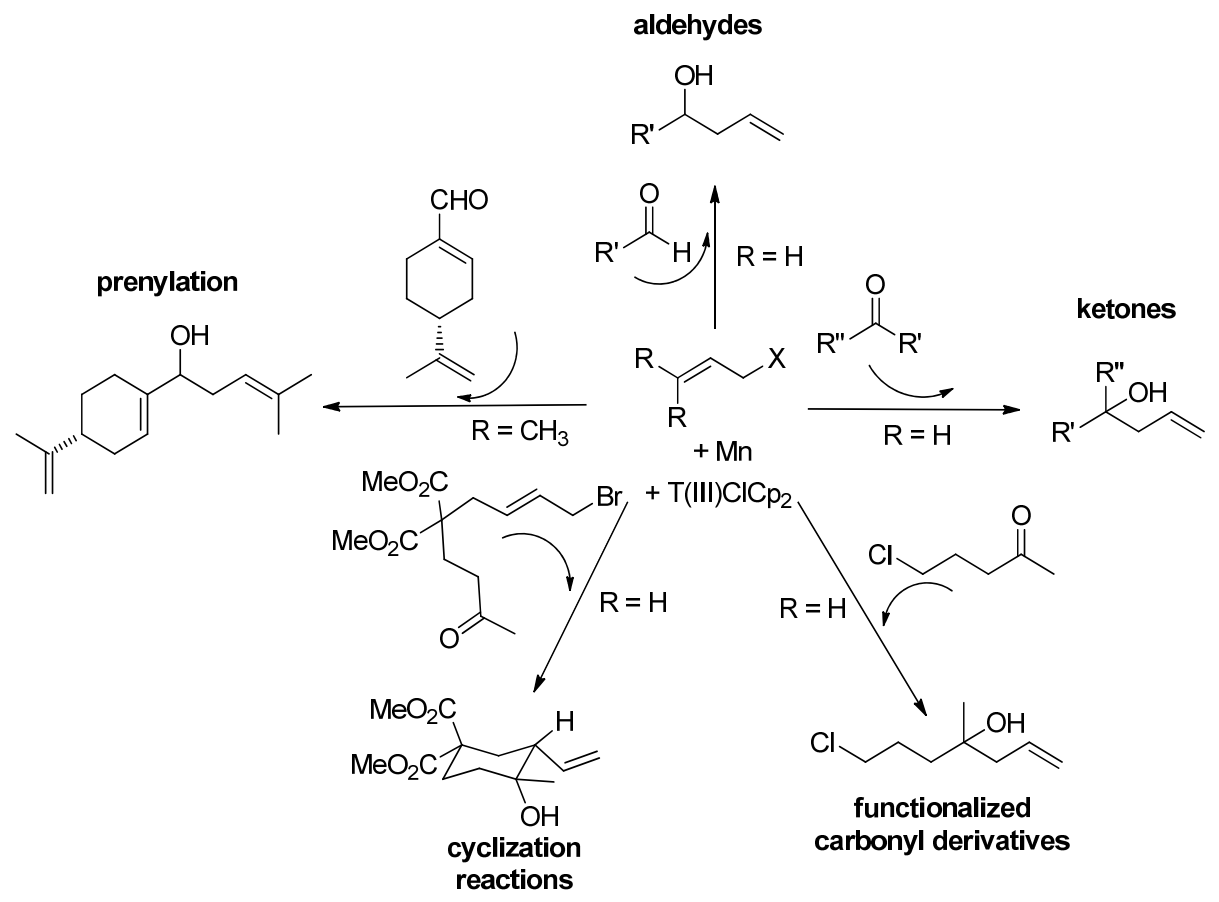

The titanocene(III)-mediated Barbier-type prenylation to $\alpha, \beta$-unsaturated aldehydes, which allows the introduction of hydroxyl groups at desiderable positions, and the subsequent radical cyclization promoted by the same titanium complex, open the straightforward access to polyhydroxylated terpenoids [57]. 
The main limitation of the Barbier-type approach is that it requires the use of allylic halides as reactive substrates, while allylic carbonates and carboxylates, which are easily prepared and handled, are inert against titanocene(III) complexes. To overcome this limit, Oltra and co-workers proposed the combination of $\mathrm{Cp}_{2} \mathrm{TiCl}$ with palladium and nickel complexes [58]. Indeed, it is well known that these metal derivatives are able to activate allylic carbonates and carboxylates by forming $\eta^{3}$-allylmetal complexes. The authors have demonstrated how the choice of the metal is crucial in modulating the $\mathrm{Cp}_{2} \mathrm{TiCl}$ activity in the allylation reaction. In fact, while palladium salts promote the intermolecular coupling with electrophilic reagents (Scheme 21a), the intramolecular allylation of alkenes with allylic carbonates occurs in the presence of nichel complexes, leading to carbocylic derivatives (Scheme 21b).

Scheme 21. Divergent Ti-mediated allylations with modulation by Palladium or Nickel.

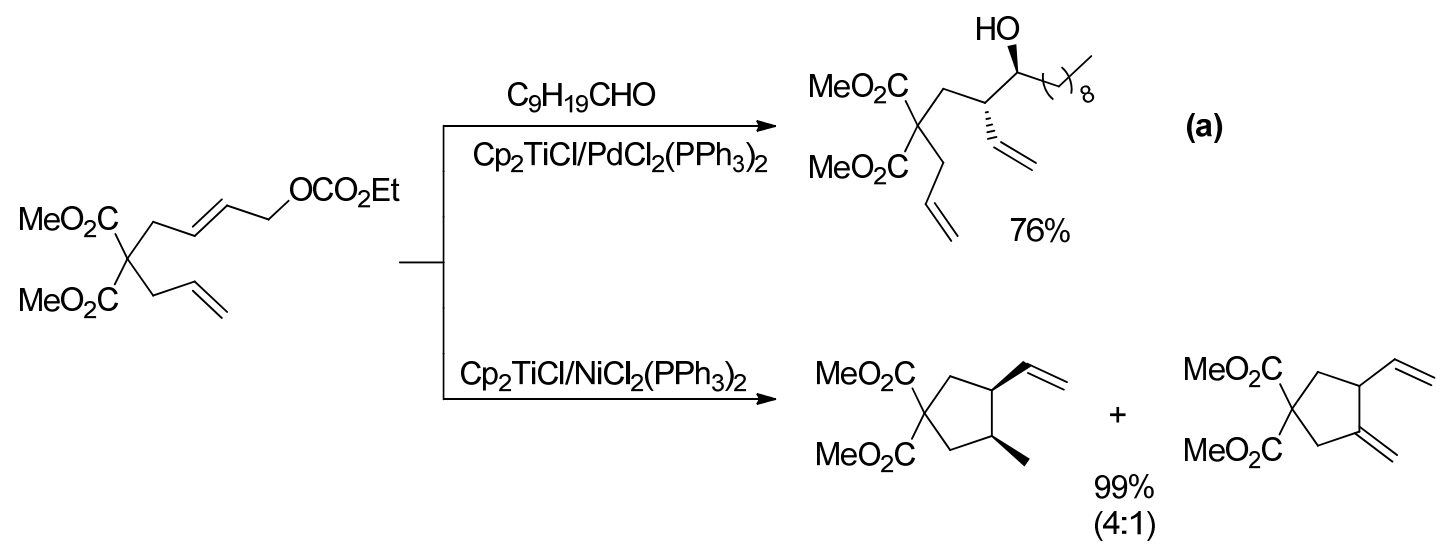

The titanium/palladium-mediated system has been successfully applied by the same research group for the selective allylation, crotylation and prenylation of aldehydes and ketones [59] (Scheme 22), for the synthesis of homopropargyl alcohols using propargyl carbonates as pronucleophiles [60] (Scheme 23), and to promote the intramolecular Michael-type addition of allylic carboxylates to activated alkenes [61] (Scheme 24). More recently, the efficient allylation of carbonyl compounds starting with allyl carbonates has been performed by replacing Pd with Ni [62].

Scheme 22. Titanium/Palladium mediated reactions.

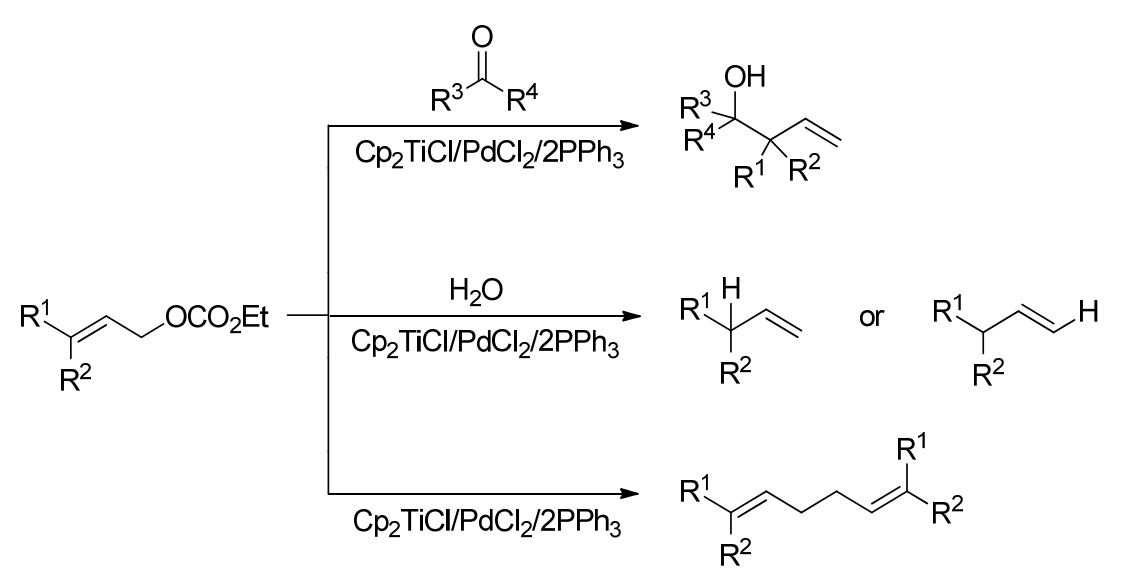


Scheme 23. Titanium/palladium-mediated propargylation of ketones.

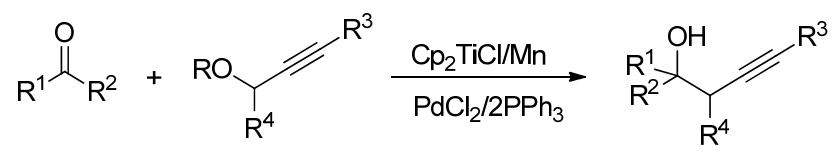

Scheme 24. Titanium/palladium-mediated intramolecular Michael-type addition.

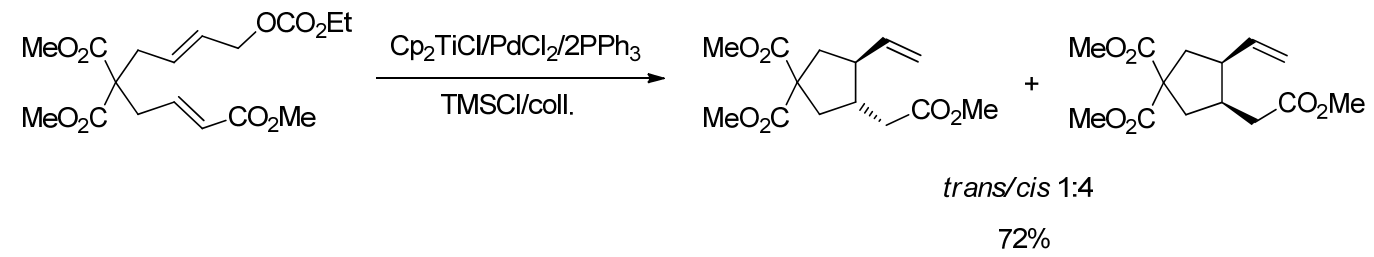

\subsection{Other Coupling Reactions}

Several other coupling reactions promoted by titanium complexes have been recently reported. Roy and co-workers have proposed the use of the $\mathrm{Cp}_{2} \mathrm{TiCl}_{2} / \mathrm{Zn}$-dust system to promote the synthesis of furan derivatives such as $( \pm)$-evodone from $\alpha$-bromo- $\beta$-keto enolethers [63]. The same approach has been successfully applied to the asymmetric synthesis of $\alpha$-methylene bis- $\gamma$-butyrolactone [64].

The $\mathrm{Cp}_{2}$ TiCl-catalyzed homolytic opening of ozonides, reported by Rosales et al. [65], provides carbon centered radicals suitable to form $\mathrm{C}-\mathrm{C}$ bonds via both homocoupling and cross-coupling processes (Scheme 25).

Scheme 25. Homocoupling versus cross-coupling in the Ti-catalyzed opening of ozonides.

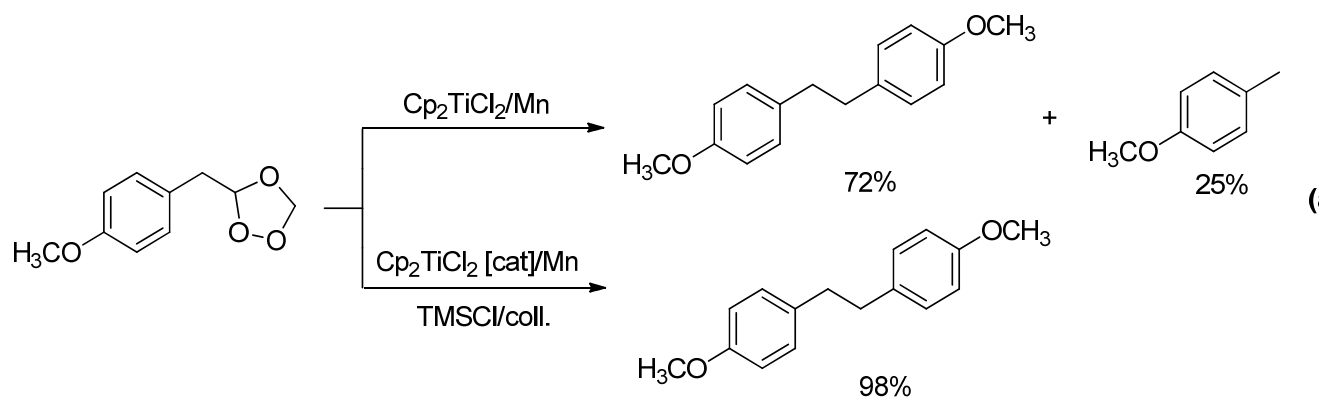

(a)

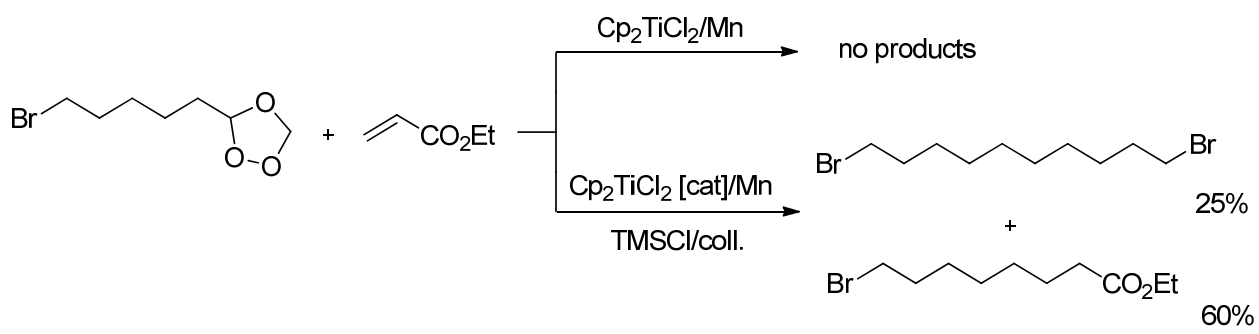

(b)

Very recently, Streuff and co-workers have reported an efficient enatioselective reductive cyclization of ketonitriles promoted and catalyzed by chiral Ti(III) catalysts (Scheme 26) [66]. 
Scheme 26. Reductive cyclization of ketonitriles.

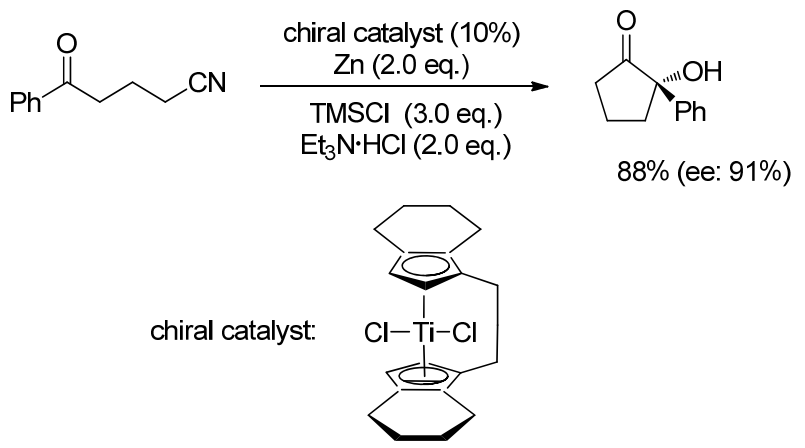

An example of the potential of radical chemistry is the use of the Ingold-Fisher "Persistent Radical Effect" (PRE) which has found ample employment in cross-coupling reactions for the selective synthesis of organic compounds. According to PRE, the cross-coupling between two radicals occurs when the two species are generated at similar rates and one is more persistent than the other, that is with a lifetime significantly greater than that for a methyl radical under the same conditions [67].

In 2008 we reported how $\alpha, \beta$-dihydroxy ketones can be used as a source of stabilized radicals via selective $\mathrm{C}-\mathrm{C}$ bond cleavage promoted by $\mathrm{TiCl}_{4}$ [68] the coordinating effect of the metal ion induces an increased stabilization onto the new radicals, driven by the captodative effect (Scheme 27).

Scheme 27. C-C bond cleavage of $\alpha, \beta$-dihydroxy ketones promoted by $\mathrm{TiCl}_{4}$.

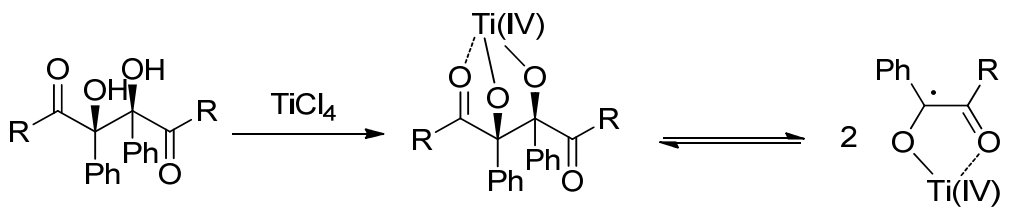

This observation prompted us to develop a new one-pot multicomponent route leading to the synthesis of polyfunctional derivatives of high added value. The generation, in the same reaction medium, of transient radicals via thermal decomposition of 2,2'-azo-bis-isobutyronitrile (AIBN) yielded an innovative methodology for the synthesis of $\beta$-hydroxynitriles by cross-combination between Ti(IV)-stabilized radicals and the $\alpha$-cyanoisopropyl radical (Scheme 28).

Scheme 28. Synthesis of $\beta$-hydroxynitriles from $\alpha, \beta$-dihydroxy ketones and AIBN.

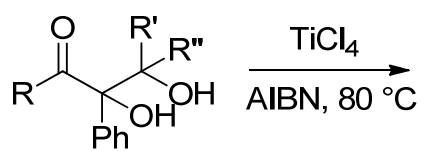

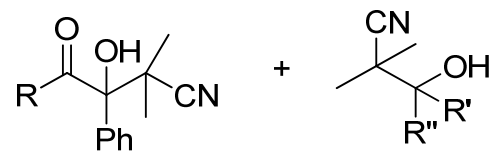

\section{Epoxide Reactions Mediated by Titanocene}

Bis (cyclopentadienyl) titanocene III chloride $\left(\mathrm{Cp}_{2} \mathrm{TiCl}\right)$ and substituted titanocenes are well known titanium complexes able to generate regioselective radical epoxide opening through single electron transfer (ET), both in stoichiometric and catalytic amounts $[69,70]$. The method of radical generation combines both the Lewis acid catalysis and the radical chemistry with interesting advantages: the initial ET by the metal, tuning the acidity of the metal center, avoids SN-type reactions, while the 
ensuing radical reaction can be controlled by the metal complex and his ligand. Cyclic voltammetry and kinetic measurements have disclosed the structure and mechanism of epoxide opening by $\mathrm{Cp}_{2} \mathrm{TiCl}$ reagents in solution: the activation of $\mathrm{Cp}_{2} \mathrm{TiCl}_{2}$ species by $\mathrm{Mn}$ or $\mathrm{Zn}$ reducing metals in THF solution leads to a mixture composed by the monomer $\mathrm{Cp}_{2} \mathrm{TiCl}$ and the chlorine bridged dimer $\left(\mathrm{Cp}_{2} \mathrm{TiCl}\right)_{2}$, but the more reactive species is the half-open dimer [71,72] (Scheme 29).

Scheme 29. Structures of $\mathrm{Cp}_{2} \mathrm{TiCl}$ in solution: dimer (a), half-open dimer (b), reactive species binding the solvent $(\mathbf{c})$.

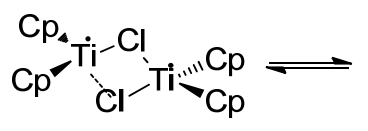

(a)

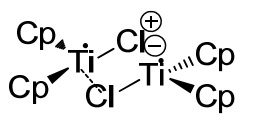

(b)

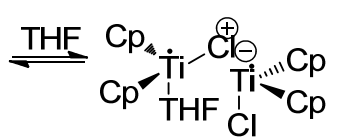

(c)

Typical radical reactions mediated by titanocene reagents regard selective reduction and deoxygenation of epoxides, $\mathrm{C}-\mathrm{C}$ bond formation processes such as cyclizations, and intermolecular additions to activated olefins $[73,74]$.

It is worth noting that, as the reaction mechanism generally proceeds via the most substituted (i.e., energetically most stable) radical, the regiochemistry is the opposite (and complementary) to that normally expected for conventional $\mathrm{SN}_{2}$-type epoxide openings with carbon nucleophiles or hydride reagents $[73,74]$.

\subsection{Epoxide Deoxygenation}

Though epoxides are usually prepared from olefins, their deoxygenation for the generation of $\mathrm{C}=\mathrm{C}$ double bonds finds ample application in highly oxidized substrates like carbohydrates and other natural derivatives $[75,76]$. The process proceeds in good to excellent yields, with exceptional chemo-selectivity.

It has been shown that the deoxygenation occurs when operating in the absence of radical acceptors and that it depends on the substitution pattern [77]. On the basis of these observations, Fernández-Mateos and co-workers have recently reported the selective synthesis of terpenoids starting from pinene-oxide derivatives [78].

Doris and co-workers reported in 2002 the $\mathrm{Cp}_{2}$ TiCl-mediated deoxigenation of the alkaloid leurosine (from Catharantus roseus), leading to anhydrovinblastine (Scheme 30), the key intermediate in the symthesis of the anticancer drug navelbine [79].

Scheme 30. Deoxygenation of leurosine.

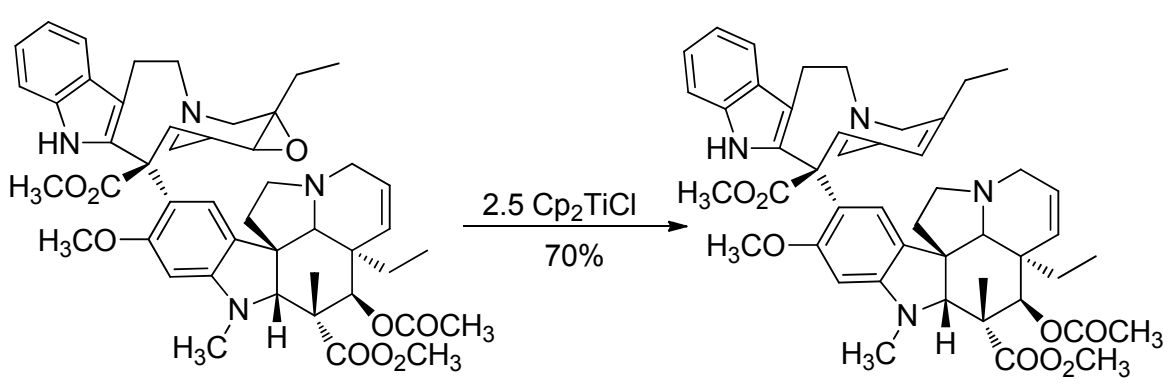


Furthermore, short and straightforward access to analogues of the natural onoceranes mediated by $\mathrm{Cp}_{2} \mathrm{TiCl}_{2}$ has been proposed by Barrero and his group [80]. The dimerization of vinyl-epoxides to 1,5 -dienes occurs via generation of very stable $\beta$-titanoxy allylradicals. The latter undergo dimerization to homo-onoceranes, followed by oxidation (Scheme 31).

Scheme 31. Dimerization of vinylepoxides for the preparation of homo-onecerans.

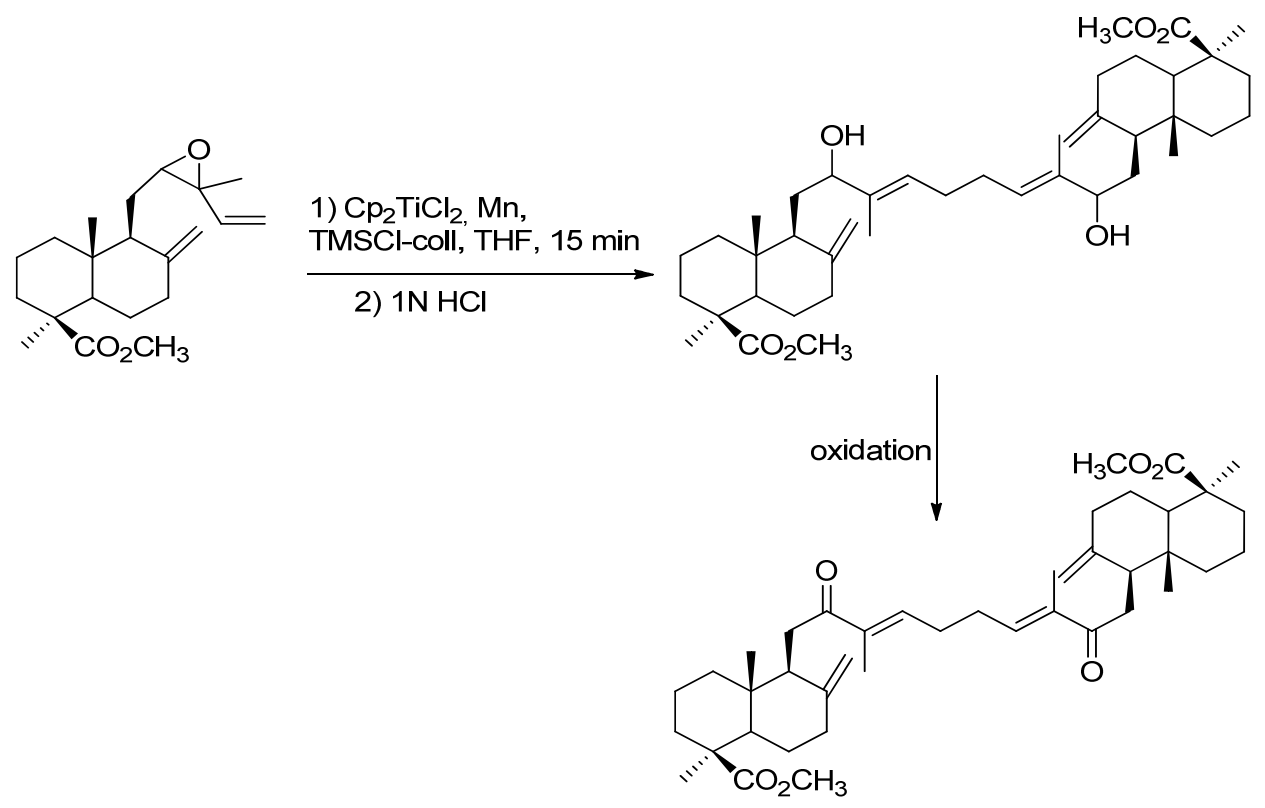

In 2009, Aldegunge et al. proposed the synthesis of alk-2-ene-1,4-diols by a new cascade-opening of 1,3-diepoxides, suggesting an alternative route to dihydroxytaxoids [81].

In the same year, Justicia et coworkers [82] showed that $\beta$-titanoxy radicals may rearrange to new trisubstituted radicals which undergo a mixed disproportionation process (via hydrogen atom transfer, Scheme 32) leading to allylic alcohols.

Scheme 32. Disproportionation of epoxide through hydrogen atom transfer.

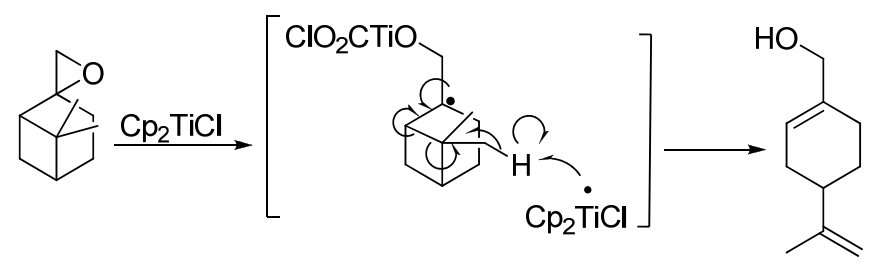

\subsection{Reductive Epoxide Opening}

The catalytic reductive epoxide opening via electron transfer from titanocenes has emerged as an attractive alternative to the classical nucleophilic substitution strategies. The titanium-mediated mechanism combines the well-established advantages of radical chemistry with a regioselectivity of ring opening opposite to that of nucleophilic substitutions, leading to a number of interesting and unusual applications in the synthesis of complex molecules [83-87]. 


\subsubsection{Synthesis of Alcohols}

According to mechanistic studies, the depicted $\beta$-tytanoxyl radical epoxide complexes constitute the first intermediate of ring opening. These radicals are then reduced by hydrogen atom donor species, like for example 1,4-cyclohexadiene (Scheme 33).

Scheme 33. Titanocene-mediated reductive epoxide opening by 1,4-cyclohexadiene.

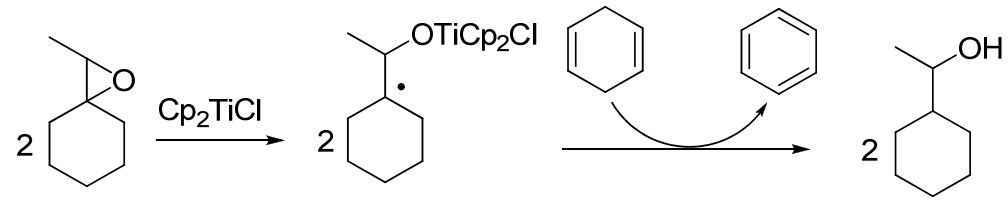

If the use of catalytic amounts of titanocenes is attractive for reagent controlled radical reactions [88], on the other hand this process presents the disadvantage deriving from the generation of stoichiometric amounts of highly toxic reducing waste, such as benzene (Scheme 26). However, it has been demonstrated that titanocene reagents are able to activate water and methanol toward hydrogen atom transfer, by substantially lowering the bond dissociation energy (BDE) of the $\mathrm{OH}$ bond [89-91]. This combination is chemically more efficient and environmentally benign. $\mathrm{Cp}_{2}$ TiCl-mediated reductive epoxide ring opening using water as a hydrogen source, allows access to alcohols with anti-Markovnikov regiochemistry from different epoxides. The use of $\mathrm{D}_{2} \mathrm{O}$ as a deuterium source, leads to an efficient synthesis of $\beta$-deuterated alcohols, which find successful application as internal standards in food analysis [92]. Another suitable hydrogen donor is $\mathrm{H}_{2}$ [93,94].

Titanocene-catalyzed procedure has been immediately extended by Gansäuer et al. to the enantioselective opening of meso-epoxides. Titanocene complexes with chiral ligands, such as those reported in Figure 2, were employed in combination with manganese dust and collidine hydrochloride, the former as a stoichiometric reductant and the latter having the role of regenerating the alcohol and titanocenes [95-102] (Scheme 34).

Figure 2. Different substitution patterns at the cyclopentadienyl ligand (Cp).
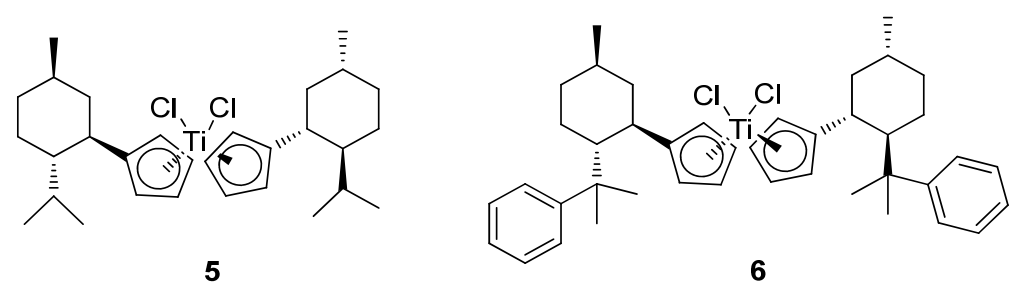

By operating in the presence of collidinium hydrochloride, the catalytic reaction could be also performed in water. This approach was exploited for the selective reduction of aromatic ketones [103,104] and the selective synthesis of 2-methyl-1,3-diol frameworks, using THF as hydrogen donor [105]. Also $\alpha, \beta$-epoxy ketones could be opened with $\mathrm{Cp}_{2} \mathrm{TiCl}$, affording $\beta$-hydroxy ketones in a better fashion than with $\mathrm{SmI}_{2}$ (Scheme 35) [106]. 
Scheme 34. Mechanism of the titanocene-catalyzed reductive epoxide opening.

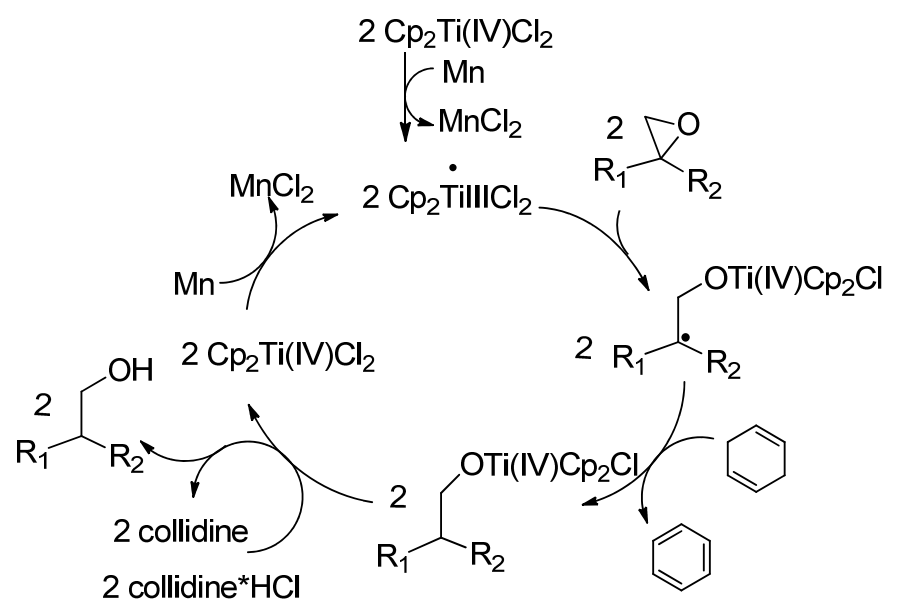

Scheme 35. Example of elective reduction of $\alpha, \beta$-epoxyketones.

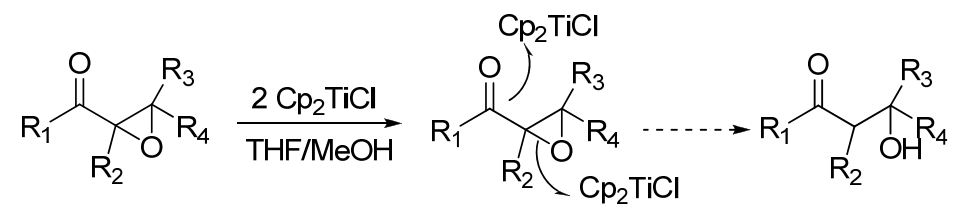

The ring-opening reaction of tri-substituted epoxides promoted by $\mathrm{Cp}_{2} \mathrm{TiCl}$ on carvone derivatives has led to exo-methylene allylic alcohols as major compounds [107]. The generation of exocyclic olefins has been reported in the course of radical cyclizations of epoxy alkenes leading to monocyclic terpens as achilleol A [108], oxobicylic drimanes [109], eudesmanolides [110], and different ring synthons of paclitaxel [111]. In these cases, termination of the radical cycle is not reductive, but rather it involves $\beta$-hydrogen elimination providing an alkene function.

Very recently Gansäuer et al. have reported a new protocol to perform the radical reduction of epoxides by hydrogen atom transfer catalyzed by the active specie $\left[\mathrm{Cp}_{2} \mathrm{TiH}\right]$ [112]. The active catalyst is generated in situ from $\left.\left[\mathrm{Cp}_{2} \mathrm{TiOC}_{2} \mathrm{H}_{5}\right)_{2}\right]$ in the presence of $\left(\mathrm{CH}_{3}\right) \mathrm{PhSiH}_{2}($ Scheme 36).

Scheme 36. Reduction of epoxides mediated by $\left.\left[\mathrm{Cp}_{2} \mathrm{TiOC}_{2} \mathrm{H}_{5}\right)_{2}\right] /\left(\mathrm{CH}_{3}\right) \mathrm{PhSiH}_{2}$ system.

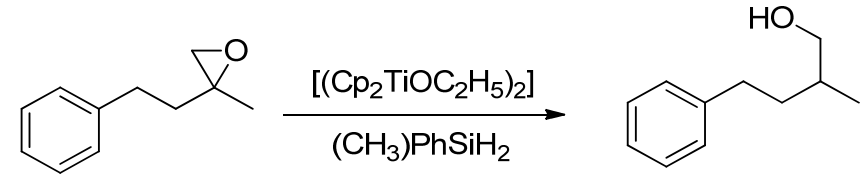

\subsubsection{Intermolecular C-C Bond Formation}

Epoxide-derived radicals generated in the presence of titanocenes are also intermediates for intermolecular $\mathrm{C}-\mathrm{C}$ bond forming reactions [113]. The resultant products, like $\delta$-hydroxyketones, esters, amides, nitriles and $\delta$-lactones, constitute important classes of intermediates in organic synthesis (Scheme 37). It has been reported that the $\mathrm{C}-\mathrm{C}$ bond formation employing $\alpha, \beta$-unsaturated tungsten and chromium carbenes, as radical acceptors of epoxide-derived radicals, occurs with high 
chemoselectivity. This approach has been applied to both sugar-derived and $\alpha, \beta$-unsaturated carbenes [114] (Scheme 38).

Scheme 37. Intermolecular C-C addition reaction.

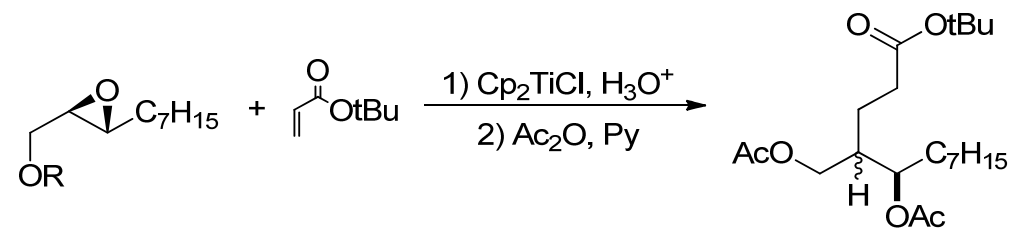

Scheme 38. Addition reactions onto carbenes.
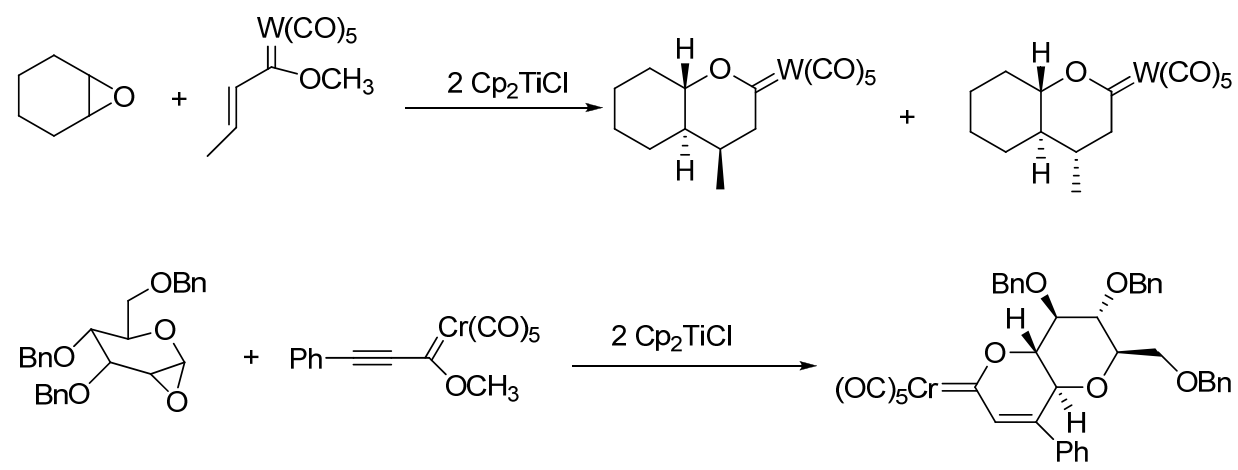

\subsubsection{Intramolecular C-C Bond Formation}

The use of $\mathrm{Cp}_{2} \mathrm{TiCl}$ (in stoichiometric or catalytic amounts) allowed to promote the synthesis of natural products by the construction of three- to six- and eight-membered carbocycles in good to excellent yields [115-120]. Small ring 3-exo and 4-exo cyclizations were achieved by nucleophilic intramolecular radical addition to aldehydes and ketones [117] and natural products, like (E)-endo-bergamoten-12-oic acids [115] or carbacephams, are significant examples of synthetic applications (Scheme 39) [121-125].

Scheme 39. 3-exo and 4-exo cyclization with aldehydes as radical traps.
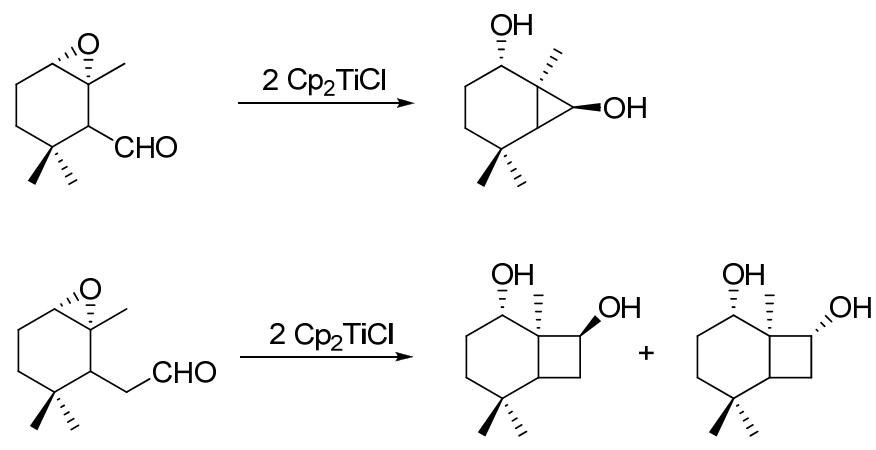

While gem-dialkyl or gem-dialkoxyl substitution is usually required to maintain an efficient propagation of the radical chain, very recently Gansäuer et al. have reported the first example of 4-exo cyclization on unsaturated epoxides without gem disubstitution [124]. This result was achieved by using cationic functionalized titanocenes as template catalysts (Scheme 40). According to the proposed 
mechanism [126], the two-point binding which occurs between the substituted radical and the template forces the radical center and the radical acceptor into close spatial proximity (Figure 3).

Scheme 40. 4-exo-cyclization of unsaturated epoxides.

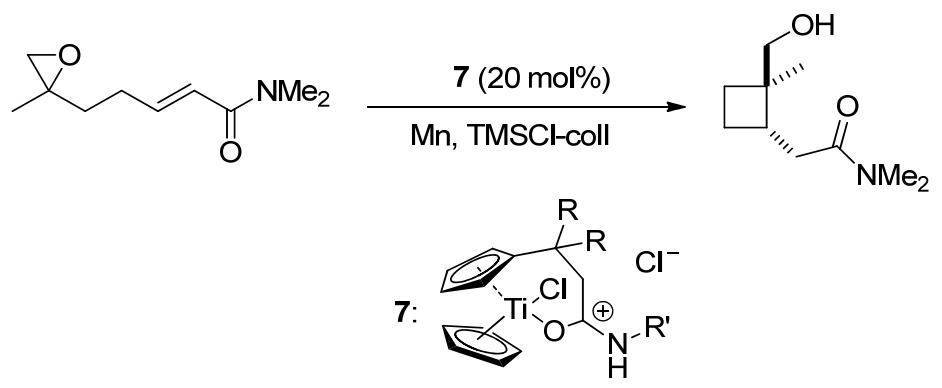

Figure 3. Possible radical intermediate in 4-exo-cyclization of unsaturated epoxides.

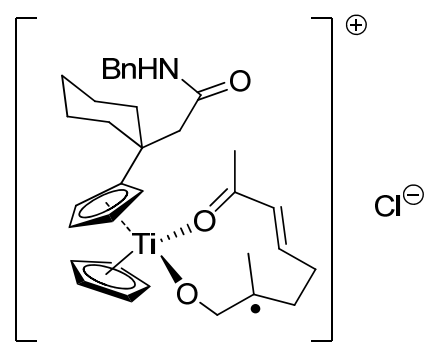

5-exo cyclizations are usually conducted by using alkenes and alkynes as radical traps and this approach has been widely applied for several synthetic routes [127-137]. Following an analogous procedure, a 6-endo cyclization employing $\mathrm{Cp}_{2} \mathrm{TiCl}$ was reported in 2001 by Takahaschi and co-workers for the synthesis of ( \pm )-smenospondiol [138]. Titanocene(III) chloride mediated 5-exo and 6-exo cyclization has been recently applied for the regio- and diastereoselective synthesis of highly functionalized terpenic cyclopentanes [139], and for the synthesis of (-)-methylenolactocin and (-)-protolichesterinic acid [140]. Titanocene-promoted cyclization of unsaturated epoxylactones was also reported as a key step for diastereoselective synthesis of limonoid CDE fragments [141].

Epoxypolyene cyclizations were performed in the presence of $\mathrm{Cp}_{2} \mathrm{TiCl}_{2}$ using the collidinechlorotrimethylsilane system, leading to exo-cyclic olefins by hydrogen atom abstraction (Scheme 41) [142-144]. These cyclization reactions proceed with high stereoselectivity giving only one of the many possible stereoisomers. Moreover, some of the cyclization products can be readily elaborated into natural products or key intermediates such as in the preparation of zonarol, a natural antifungal (Scheme 42).

Scheme 41. Catalytic epoxypolyene cyclization.

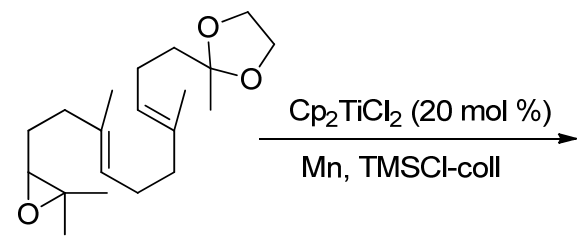<smiles></smiles> 
Scheme 42. Tandem cyclization approach for meroterpenoid (+)-zonarol synthesis.
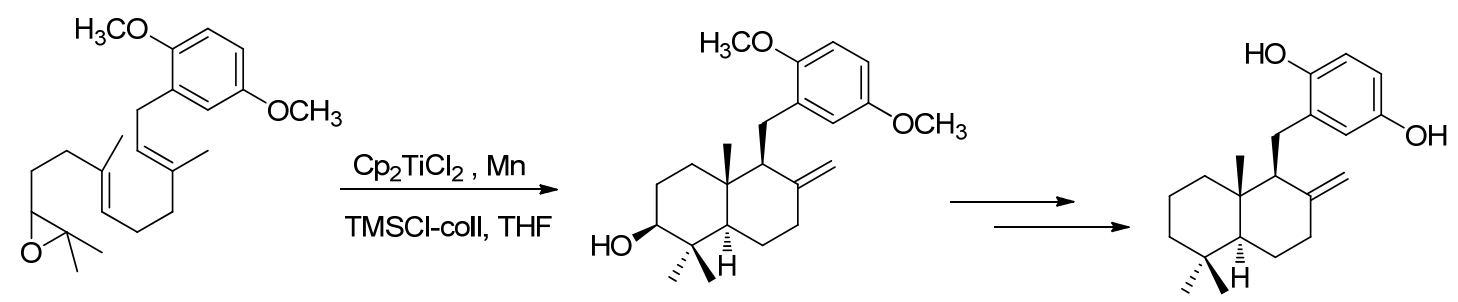

Following the same procedure, 7-endo cyclizations can be performed in surprisingly high yields (Scheme 43) [145]. Finally, 8-endo cyclizations have been reported by Roy and his group for the preparation of aromatic ethers [146].

Scheme 43. 7-endo cyclization.<smiles>C=CC(C)(CCC1=CCCC=C1CCC1OC1C)OC(C)=O</smiles><smiles>CC(C)(C)OCCOC(C)(C)C</smiles><smiles>CC1=CCC2(C)CC[C@H]3[C@H](C)C(O)CCC3(C)[C@H]2CC1</smiles>

\section{Living Polymerizations}

Several metal complexes were designed and tested to effectively control the radical polymerization of a number of polar olefins, leading to the synthesis of complex macromolecular architectures [147,148].

The use of titanium complexes for this purpose is relatively rare. Nevertheless, in recent years it has been emphasized the $\mathrm{Ti}(\mathrm{III}) / \mathrm{Ti}$ (IV) capacity of modulating the equilibrium in atom transfer reactions. As a consequence, this redox pair was reported as a very active catalytic system for atom transfer radical polymerization [149].

Radical controlled polymerization reactions by epoxide radical ring opening (RRO) have been performed in the presence of $\mathrm{Cp}_{2} \mathrm{TiCl}_{2}$ in combination with $\mathrm{Zn}$ powder [150-152]. According to this approach, methyl methacrylate (MMA) polymerization has been performed with high-molecular weight in aqueous conditions $(\mathrm{Mw}=51,000-73,000)$. An analogous route has been recently reported for the radical polymerization of styrene [151]. The $\mathrm{Ti}(\mathrm{III}) \mathrm{Cp}_{2} \mathrm{Cl}$-catalyzed RRO of epoxides produces Ti-alkoxides, which initiate the ring opening polymerization of cyclic esters like $\varepsilon$-caprolactone (Scheme 44) [153], the radical polymerization of isoprene [154] and styrene/isoprene copolymers [155].

The ligand effect in Ti-mediated living radical styrene polymerizations initiated by epoxide RRO has been widely investigated by Asandei and Moran, focusing in particular onto alkoxide and bisketonate titanium complexes [156], scorpionate and half-sandwich $\mathrm{LTiCl}_{3}$ derivatives [157] and substituted sandwich metallocenes [158]. Moreover, the same research group disclosed in detail the role of solvents and additives for this polymerization reactions [159], the effect of the reducing agent and temperature, as well as of the ratio titanium/epoxide and titanium/zinc [160]. 
Scheme 44. RRO of epoxides for the initiation of the living polymerization of e-caprolactone.

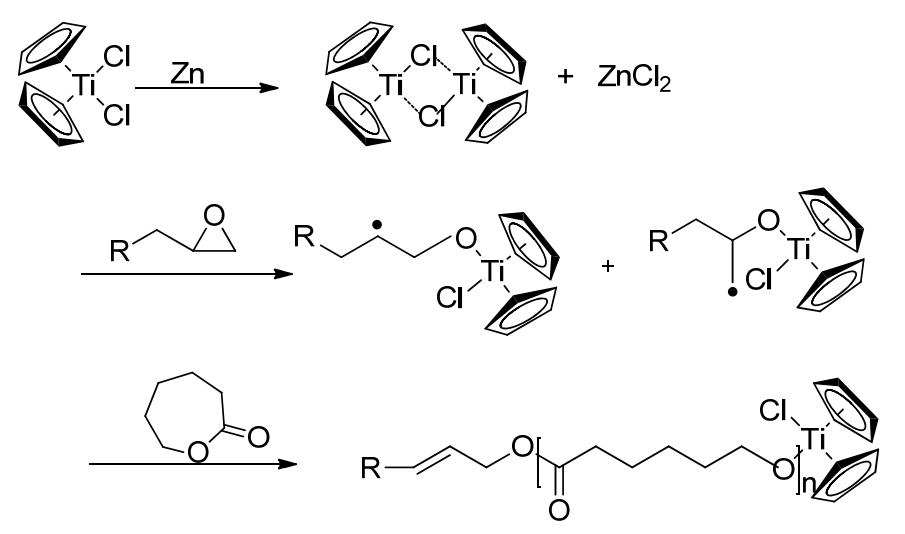

Excellent results in the living radical polymerization were also achieved by initiating the process via single electron transfer reduction of aldehydes promoted by $\mathrm{Cp}_{2} \mathrm{TiCl}$ [161]. This approach has been successfully applied also for the polymerization of $\varepsilon$-caprolactone [162].

Very recently, $\mathrm{Cp}_{2} \mathrm{TiCl}_{2}$ has been applied in the field of photopolymerization for applications requiring safe conditions (Scheme 45) [163]. $\mathrm{Cp}_{2} \mathrm{TiCl}_{2} /$ silane (tris(trimethylsilyl)silane TTMSS)/ iodonium salt $\left(\mathrm{Ph}_{2} \mathrm{I}^{+}\right)$resulted to be a good photoinitiating system in the free radical promoted cationic photopolymerization process of an epoxide monomer (EPOX) upon long wavelength excitation $(\lambda>400 \mathrm{~nm})$. Under visible LED bulbs, xenon lamp and laser diodes, the reactions exhibit an excellent performance and a remarkable final polymerization close to $100 \%$. The basic idea is to produce a radical (from a photoinitiating system) which, in turn, should be oxidized by the iodonium salt: $\mathrm{Cp}_{2} \mathrm{TiCl}_{2}$ generates under argon cyclopentadienyl radicals $\left(\mathrm{Cp}^{\circ}\right)$ and/or metal-centered radicals $\mathrm{CpTi}^{\circ} \mathrm{Cl}_{2}$. In the presence of TTMSS, $\mathrm{Cp}{ }^{*}$ can rapidly react by hydrogen abstraction with the silane Si-H generating a silyl radical. The latter can be easily oxidized by $\mathrm{Ph}_{2} \mathrm{I}^{+}$with a rate constant of $2.6 \times 10^{6} \mathrm{M}^{-1} \mathrm{~s}^{-1}$, leading to the formation of a silylium cation, which, in turn, can initiate the cationic polymerization by ring-opening of EPOX.

Scheme 45. Polymerization of EPOX mediated by titanocene.

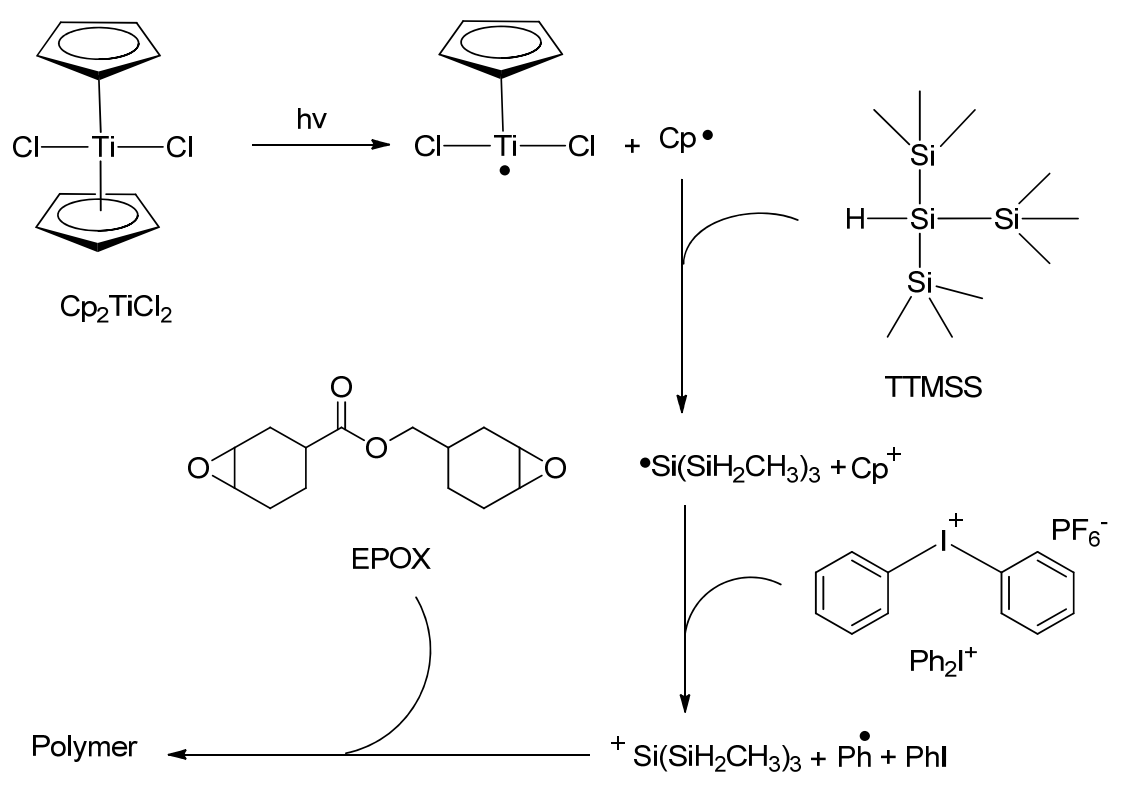




\section{Conclusions}

This study covers the literature over the past twelve years emphasizing the key role that titanium salts and complexes play in promoting synthetic free-radical processes. While several excellent reviews, focusing on specific Ti-mediated reactions and defined product targets or on the general role of transition metals in promoting radical chains, have been recently published, to the best of our knowledge this work represents the first comprehensive contribution which outlines the potential of titanium catalysis in radical reactions, analytically overviewing the recent progresses in selective freeradical organic synthesis.

Though multicomponent procedures are of great interest for the development of new synthetic routes, examples in the field of radical reactions are in general scant. Among the few protocols recently reported, the nucleophilic radical addition to imines mediated by $\mathrm{Ti}(\mathrm{III}) / \mathrm{Ti}(\mathrm{IV})$ systems represents an innovative one-pot approach leading to a wide range of intriguing functionalized derivatives under very mild experimental conditions.

Pinacolization of aldehydes is particularly attractive, not only for the importance of the final diols, but also because it represents a significant model for investigating enantioselectivity in radical chemistry. Other radical coupling reactions, when mediated by titanium complexes, lead to high added value products with chemo- and stereo-selectivity.

Finally, deoxygenation or reductive ring opening of epoxides by means of titanocenes find ample use in the synthesis of natural and biologically active molecules. Ti-mediated radical ring opening of epoxides is also successfully applied to promote living radical polymerization of olefins (such as styrene and isoprene) and lactones (for example $\varepsilon$-caprolactone).

The development and optimization of titanium ligands, including the introduction of chiral complexes, allows in many cases to perform stero- and/or enantio-selective syntheses of the desired products. The ongoing research for the design, synthesis, and application of these new ligands guarantees the development of new Ti-based catalytic systems for selective transformations under very mild conditions.

\section{Acknowledgments}

We thank MIUR for continual support of our free-radical (PRIN 2008, project 2008KRBLP5_003) and organic (FIRB-Future in Research 2008, project RBFR08XH0H_001) chemistry.

\section{References}

1. Barton, D.H.; Beaton, J.M.; Geller, L.E.; Pechet, M.M. A new photochemical reaction. J. Am. Chem. Soc. 1960, 82, 2640-2641.

2. Renaud, P., Sibi, M.P., Eds. Radicals in Organic Synthesis; Wiley-VCH: Weinheim, Germany, 2001; Volumes 1 and 2.

3. Chatgilialoglu, C., Studer, A., Eds. Encyclopedia of Radicals in Chemistry, Biology and Materials; Wiley: Chichester, UK, 2012; Volumes 1 and 2.

4. Jahn, U. Radicals in transition metal catalyzed reactions? Transition metal catalyzed radical reactions? A fruitful interplay anyway: Part 1. Radical catalysis by group 4 to group 7 elements. Top. Curr. Chem. 2012, 320, 121-189. 
5. Jahn, U. Radicals in transition metal catalyzed reactions? Transition metal catalyzed radical reactions? A fruitful interplay anyway: Part 2. Radical catalysis by group 8 and 9 elements. Top. Curr. Chem. 2012, 320, 191-322.

6. Jahn, U. Radicals in transition metal catalyzed reactions? Transition metal catalyzed radical reactions? A fruitful interplay anyway: Part 3. Radical catalysis by group 10 and 11 elements and bimetallic catalysis. Top. Curr. Chem. 2012, 320, 323-451.

7. Yorimitsu, H. Transition metals and Radicals. In Encyclopedia of Radicals in Chemistry, Biology and Materials; Chatgilialoglu, C., Studer, A., Eds.; Wiley: Chichester, UK, 2012; Volume 2, pp. 1003-1018.

8. Burton, J. Manganese (III) acetate, CAN, and Fe(III) salts in oxidative radical chemistry. In Encyclopedia of Radicals in Chemistry, Biology and Materials; Chatgilialoglu, C., Studer, A., Eds.; Wiley: Chichester, UK, 2012; Volume 2, pp. 901-941.

9. Recupero, F.; Punta, C. Free Radical functionalization of organic compounds catalyzed by N-hydroxyphthalimide. Chem. Rev. 2007, 107, 3800-3842.

10. Minisci, F.; Recupero, F.; Cecchetto, A.; Gambarotti, C.; Punta, C.; Faletti, R.; Paganelli, R.; Pedulli, G.F. Mechanisms of the aerobic oxidation of alcohols to aldehydes and ketones, catalysed under mild conditions by persistent and non-persistent nitroxyl radicals and transition metal salts - Polar, enthalpic, and captodative effects. Eur. J. Org. Chem. 2004, 109-119.

11. Coote, S.C.; Flowers, R.A., II; Skrydstrup, T.; Procter, D.J. Organic synthesis using samarium diiodide. In Encyclopedia of Radicals in Chemistry, Biology and Materials; Chatgilialoglu, C., Studer, A., Eds.; Wiley: Chichester, UK, 2012; Volume 2, pp. 849-900.

12. Friestad, G.K. Asymmetric radical addition to chiral hydrazones. In Topics in Current Chemistry: Radicals in Synthesis III; Gansauer A., Heinrich, M., Eds.; Springer-Verlag: Berlin, Germany, 2012; Volume 320, pp. 61-92.

13. Friestad, G.K. Organomanganese-mediated radical reactions. In The Chemistry of OrganoManganese Compounds; Marek, I., Rappoport, Z., Eds.; Wiley: Chichester, UK, 2011; pp. 559-584.

14. Yamada, K.; Tomioka, K. Copper-catalyzed asymmetric alkylation of imines with dialkylzinc and related reactions. Chem. Rev. 2008, 108, 2874-2886.

15. Akindele, T.; Yamada, K.; Tomioka, K. Dimethylzinc-initiated radical reactions. Acc. Chem. Res. 2009, 42, 345-355.

16. Pastori, N.; Gambarotti, C.; Punta, C. Recent developments in nucleophilic radical addition to imines: The key role of transition metals and the new Porta radical-type version of the Mannich and Strecker Reactions. Mini-Rev. Org. Chem. 2009, 6, 184-195.

17. Miyabe, H.; Yoshioka, E.; Kohtani, S. Progress in intermolecular carbon radical addition to imine derivatives. Curr. Org. Chem. 2010, 14, 1254-1264.

18. Rowlands, G.J. Radicals in organic synthesis. Part 1. Tetrahedron 2009, 65, 8603-8655.

19. Rowlands, G.J. Radicals in organic synthesis. Part 2. Tetrahedron 2010, 66, 1593-1636.

20. Kamigaito, M.; Ando, T.; Sawamoto, M. Metal-catalyzed living radical polymerization. Chem. Rev. 2001, 101, 3689-3745.

21. Ouchi, M.; Terashima, T.; Sawamoto, M. Transition metal-catalyzed living radical polymerization: toward perfection in catalysis and precision polymer synthesis. Chem. Rev. 2009, 109, 4963-5050. 
22. Pintauer, T.; Matyjaszewski, K. Atom transfer radical addition and polymerization reactions catalyzed by ppm amounts of copper complexes. Chem. Soc. Rev. 2008, 37, 1087-1097.

23. Gaya, U.I.; Abdullah, A.H. Heterogeneous photocatalytic degradation of organic contaminants over titanium dioxide: A review of fundamentals, progress and problems. J. Photochem. Photobiol. C. 2008, 9, 1-12.

24. Gambarotti, C.; Punta, C.; Recupero, F.; Caronna, T.; Palmisano, L. $\mathrm{TiO}_{2}$ in organic photosynthesis: Sunlight induced functionalization of heterocyclic bases. Curr. Org. Chem. 2010, 14, 1153-1169.

25. Fagnoni, M.; Dondi, D.; Ravelli, D.; Albini, A. Photocatalysis for the formation of the C-C bond. Chem. Rev. 2007, 107, 2725-2756.

26. Visai, L.; De Nardo, L.; Punta, C.; Melone, L.; Cigada, A.; Imbriani, M.; Arciola, C.R. Titanium oxide antibacterial surfaces in biomedical devices. Int. J. Artif. Org. 2011, 34, 929-946.

27. Friestad, G.K.; Ji, A.; Baltrusaitis, J.; Korapala, C.S.; Qin, J. Scope of stereoselective Mn-mediated radical addition to chiral hydrazones and application in a formal synthesis of quinine. J. Org. Chem. 2012, 77, 3159-3180.

28. Fujihara, H.; Nagai, K.; Tomioka, K. Copper-amidophosphine catalyst in asymmetric addition of organozinc to Imines. J. Am. Chem. Soc. 2000, 122, 12055-12056.

29. Nagai, K.; Fujihara, H.; Kuriyama, M.; Yamada, K.; Tomioka, K. Efficient chiral amidophosphine ligand for copper-catalyzed asymmetric addition of diethylzinc to $N$-sulfonylimines. Chem. Lett. 2002, 31, 8-9.

30. Soeta, T.; Nagai, K.; Fujihara, H.; Kuriyama, M.; Tomioka, K. Asymmetric alkylation of N-toluenesulfonylimines with dialkylzinc reagents catalyzed by copper-chiral amidophosphine. J. Org. Chem. 2003, 68, 9723-9727.

31. Porter, J.R.; Traverse, J.F.; Hoveyda, A.H.; Snapper, M.L. Enantioselective synthesis of arylamines through $\mathrm{Zr}$-catalyzed addition of dialkylzincs to imines. Reaction development by screening of parallel libraries. J. Am. Chem. Soc. 2001, 123, 984-985.

32. Porter, J.R.; Traverse, J.F.; Hoveyda, A.H.; Snapper, M.L. Three-component catalytic asymmetric synthesis of aliphatic amines. J. Am. Chem. Soc. 2001, 123, 10409-10410.

33. Akullian, L.C.; Snapper, M.L.; Hoveyda, A.H. Three-component enantioselective synthesis of propargylamines through $\mathrm{Zr}$-catalyzed additions of alkyl zinc reagents to alkynylimines. Angew. Chem. Int. Ed. 2003, 42, 4244-4247.

34. Clerici, A.; Porta, O. Arylative amination of aldehydes promoted by aqueous titanium trichloride. Tetrahedron Lett. 1990, 31, 2069-2072.

35. Cannella, R.; Clerici, A.; Pastori, N.; Regolini, E.; Porta, O. One-pot four-component reaction: Aqueous $\mathrm{TiCl}_{3} / \mathrm{PhN}_{2}{ }^{+}$-mediated alkyl radical addition to imines generated in situ. Org. Lett. 2005, 7, 645-648.

36. Clerici, A.; Cannella, R.; Panzeri, W.; Pastori, N.; Regolini, E.; Porta, O. $\mathrm{TiCl}_{3} / \mathrm{PhN}_{2}{ }^{+}$-mediated radical addition of ethers to aldimines generated in situ under aqueous conditions. Tetrahedron Lett. 2005, 46, 8351-8354.

37. Clerici, A.; Cannella, R.; Panzeri, W.; Porta, O. A Free radical Mannich type reaction: selective $\alpha-\mathrm{CH}$-aminomethylation of ethers by $\mathrm{Ti}(\mathrm{III}) / \mathrm{t}-\mathrm{BuOOH}$ system under aqueous acidic conditions. Tetrahedron 2006, 62, 5986-5994. 
38. Cannella, R.; Clerici, A.; Panzeri, W.; Pastori, N.; Punta, C.; Porta, O. Free-radical version of Strecker Synthesis of $\alpha$-aminomides promoted by aqueous $\mathrm{H}_{2} \mathrm{O}_{2} / \mathrm{TiCl}_{3} / \mathrm{HCONH}_{2}$ System. J. Am. Chem. Soc. 2006, 128, 5358-5359.

39. Clerici, A.; Ghilardi, A.; Pastori, N.; Punta, C. A new one-pot, four-component synthesis of 1,2-amino alcohols: $\mathrm{TiCl}_{3} / \mathrm{t}-\mathrm{BuOOH}$-mediated radical hydroxymethylation of imines. Org. Lett. 2008, 10, 5063-5066.

40. Spaccini, R.; Ghilardi, A.; Pastori, N.; Clerici, A.; Porta, O.; Punta, C. Efficient radical domino approach to $\beta$-aminoalcohols from arylamines and alcohols triggered by $\mathrm{Ti}(\mathrm{III}) / \mathrm{t}-\mathrm{BuOOH}$. Tetrahedron 2010, 66, 2044-2052.

41. Clerici, A.; Greco, C.; Panzeri, W.; Pastori, N.; Punta, C.; Porta, O. Reductive coupling of aromatic aldehydes promoted by an aqueous $\mathrm{TiCl}_{3} / \mathrm{t}-\mathrm{BuOOH}$ system in alcoholic cosolvents. Eur. J. Org. Chem. 2007, 4050-4055.

42. Pastori, N.; Greco, C.; Clerici, A.; Punta, C.; Porta, O. Free-Radical addition to ketimines generated in situ. One-pot synthesis of quaternary $\alpha$-aminomides promoted by a $\mathrm{H}_{2} \mathrm{O}_{2} / \mathrm{TiCl}_{4}-\mathrm{Zn} / \mathrm{HCONH}_{2}$ system. Org. Lett. 2010, 12, 3898-3901.

43. Rossi, B.; Pastori, N.; Clerici, A.; Punta, C. Free-radical hydroxymethylation of ketimines generated in situ: A one-pot multicomponent synthesis of $\beta, \beta$-disubstituted- $\beta$-aminoalcohols. Tetrahedron 2012, 68, 10151-10156.

44. Prosperini, S.; Pastori, N.; Ghilardi, A.; Clerici, A.; Punta, C. New domino radical synthesis of aminoalcohols promoted by $\mathrm{TiCl}_{4}-\mathrm{Zn} / \mathrm{t}-\mathrm{BuOOH}$ system: selective hydroxyalkylation of amines in alcohol or in cyclic ether cosolvents. Org. Biomol. Chem. 2011, 9, 3759-3767.

45. Saha, S.; Roy, S.C. Titanocene(III) chloride mediated radical induced allylation of aldimines: Formal synthesis of C-linked 40-deoxy aza-disaccharide. J. Org. Chem. 2011, 76, 7229-7234.

46. Ramón, D.J.; Yus, M. In the arena of enantioselective synthesis, titanium complexes wear the laurel wreath. Chem. Rev. 2006, 106, 2126-2208.

47. Szymoniak, J.; Mose, C. Synthesis and reactivity of allyltitanium derivatives. In Titanium and Zirconium in Organic Synthesis; Marek, I., Ed.; Wiley-VCH: Weinheim, Germany, 2002; pp. 451-474.

48. Chatterjee, A.; Joshi, N.N. Evolution of the stereoselective pinacol coupling reaction. Tetrahedron 2006, 62, 12137-12158.

49. Clerici, A.; Clerici, L.; Porta, O. A highly dl-stereoselective pinacolization of aromatic aldehydes mediated by titanium trichloride in dichloromethane. Tetrahedron Lett. 1996, 37, 3035-3038.

50. Clerici, A.; Pastori, N.; Porta, O. On the paradox of $\mathrm{TiCl}_{4}$ reducing power: pinacol coupling and two-carbon homologation of carbonyl compounds. Tetrahedron Lett. 2004, 45, 1825-1827.

51. Paradas, M.; Campaña, A.G.; Estévez, R.E.; de Cienfuegos, L.A.; Jiménez, T.; Robles, R.; Cuerva, J.M.; Oltra, J.E. Unexpected $\mathrm{Ti}^{\mathrm{III}} / \mathrm{Mn}$-promoted pinacol coupling of ketones. J. Org. Chem. 2009, 74, 3616-3619.

52. Bensari, A.; Renaud, J.-L.; Riant, O. Enantioselective pinacol coupling of aldehydes mediated and catalyzed by chiral titanium complexes. Org. Lett. 2001, 3, 3863-3865.

53. Chatterjee, A.; Bennur, T.H.; Joshi, N.N. Truly catalytic and enantioselective pinacol coupling of aryl aldehydes mediated by chiral Ti(III) complexes. J. Org. Chem. 2003, 68, 5668-5671. 
54. Knoop, C.A.; Studer, A. A new method for the generation of Ti(III) complexes and its application in pinacol coupling reactions. Adv. Synth. Catal. 2005, 347, 1542-1546.

55. Sancho-Sanz, I.; Miguel, D.; Millán, A.; Estévez, R.E.; Oller-López, J.L.; Álvarez-Manzaneda, E.; Robles, R.; Cuerva, J.M.; Justicia, J. Titanocene(III)-promoted Barbier-type crotylation of carbonyl compounds. J. Org. Chem. 2011, 76, 732-735.

56. Estévez, R.E.; Justicia, J.; Bazdi, B.; Fuentes, N.; Paradas, M.; Choquesilo-Lazarte, D.; Garcia-Ruiz, J.M.; Robles, R.; Gansäuer, A.; Cuerva, J.M.; Oltra, J.E. Ti-catalyzed Barbier-type allylations and related reactions. Chem. Eur. J. 2009, 15, 2774-2791.

57. Jiménez, T.; Morcillo, S.P.; Martin-Lasanta, A.; Collado-Sanz, D.; Cárdenas, D.J.; Justicia, J.; Cuerva, J.M. Combining the power of $\mathrm{Ti}^{\mathrm{III}}$-mediated processes for easy access to hydroxylated polycyclic terpenoids: Synthesis of sesterstatin 1 and C-D rings of aspergilloxide. Chem. Eur. J. 2012, 18, 12825-12833.

58. Campaña, A.G.; Bazdi, B.; Fuentes, N.; Robles, R.; Cureva, J.M.; Oltra, J.E.; Porcel, S.; Echavarren, A.M. Divergent Titanium-Mediated Allylations with Modulation by Nickel or Palladium. Angew. Chem. Int. Ed. 2008, 47, 7625-7629.

59. Millán, A.; Campaña, A.G.; Bazdi, B.; Miguel, D.; de Cienfuegos, L.A.; Echavarren, A.M.; Cuerva, J.M. Ti/Pd bimetallic systems for the efficient allylation of carbonyl compounds and homocoupling reactions. Chem. Eur. J. 2011, 17, 3985-3994.

60. Millán, A.; de Cienfuegos, L.A.; Martin-Lasanta, A.; Campaña, A.G.; Cuerva, J.M. Titanium/Palladium-mediated regioselective propargylation of ketones using propargylic carbonates as pronucleophiles. Adv. Synth. Catal. 2011, 353, 73-78.

61. Millán, A.; Martin-Lasanta, A.; Miguel, D.; de Cienfuegos, L.A.; Cuerva, J.M. Ti/Pd-promoted intramolecular Michael-type addition of allylic carboxylates to activated alkenes. Chem. Commun. 2011, 47, 10470-10472.

62. Martínez-Peragón, Á.; Millán, A.; Campaña, A.G.; Rodríguez-Márquez, I.; Resa, S.; Miguel, D.; de Cienfuegos, L.A.; Cuerva, J.M. Ti/Ni-based multimetallic system for the efficient allylation of carbonyl compounds. Eur. J. Org. Chem. 2012, 1499-1503.

63. Mandal, S.K.; Paira, M.; Roy, S.C. Titanium(III) chloride mediated synthesis of furan derivatives: Synthesis of ( \pm )-evodone. J. Chem. Sci. 2010, 122, 423-426.

64. Saha, S.; Mandal, S.K.; Roy, S.C. Titanocene(III) chloride mediated radical induced asymmetric synthesis of $\alpha$-methylene bis- $\gamma$-butyrolactone. Tetrahedron Lett. 2011, 52, 3128-3130.

65. Rosales, A; Muñoz-Bascón, J.; López-Sánchez, C.; Álvarez-Corral, M.; Muñoz-Dorado, M.; Rodríguez-García, I.; Oltra, J.E. Ti-catalyzed homolytic opening of ozonides: A sustainable $\mathrm{C}-\mathrm{C}$ bond-forming reaction. J. Org. Chem. 2012, 77, 4171-4176.

66. Streuff, J.; Feurer, M.; Bichovski, P.; Frey, G.; Gellrich, U. Enantioselective Titanium(III)-catalyzed reductive cyclization of ketonitriles. Angew. Chem. Int. Ed. 2012, 51, 8661-8664.

67. Griller, D.; Ingold, K.U. Persistent carbon-centered radicals. Acc. Chem. Res. 1976, 9, 13-19.

68. Spaccini, R.; Pastori, N.; Clerici, A.; Punta, C.; Porta, O. Key role of Ti(IV) in the selective radical-radical cross-coupling mediated by the Ingold-Fischer effect. J. Am. Chem. Soc. 2008, 130, 18018-18024.

69. Gansäuer, A.; Justicia, J.; Fan, C.-A.; Worgull, D.; Piestert, F. Reductive C-C bond formation after opening via electron transfer. Top. Curr. Chem. 2007, 279, 25-52. 
70. Gansäuer, A.; Lauterbach, T.; Narayan, S. Strained heterocycles in radical chemistry. Angew. Chem. Int. Ed. 2003, 42, 5556-5573.

71. Daasbjerg, K.; Svith, H.; Grimme, S.; Gerenkamp, M.; Muck-Lichtenfeld, C.; Gansäuer, A.; Barchuk, A.; Keller, F. Elucidation of the mechanism of titanocene-mediated epoxide opening by a combined experimental and theoretical approach. Angew. Chem. Int. Ed. 2006, 45, 2041-2044.

72. Gansäuer, A.; Barchuk, A.; Keller, F.; Schmitt, M.; Grimme, S.; Gerenkamp, M.; Muck-Lichtenfeld, C.; Daasbjerg, K.; Svith, H. Mechanism of titanocene-mediated epoxide opening through homolytic substitution. J. Am. Chem. Soc. 2007, 129, 1359-1371.

73. RajanBabu, T.V.; Nugent, W.A. Intermolecular addition of epoxides to activated olefins: a new reaction. J. Am. Chem. Soc. 1989, 111, 4525-4527.

74. RajanBabu, T.V.; Nugent, W.A.; Beattie, M.S. Free radical-mediated reduction and deoxygenation of epoxides. J. Am. Chem. Soc. 1990, 112, 6408-6409.

75. Cuerva, J.M.; Juan, J.C.; Justicia, J.; Oller-Lòpez, J.L.; Oltra, J.E. Cp $\mathrm{p}_{2} \mathrm{TiCl}$ in natural product synthesis. Top. Curr. Chem. 2006, 264, 63-91.

76. Gansäuer, A.; Fleckhaus, A. Epoxides in titanocenes-mediated and-catalyzed radical reactions. In Encyclopedia of Radicals in Chemistry, Biology and Materials; Chatgilialoglu, C., Studer, A., Eds.; Wiley: Chichester, UK, 2012; Volume 2, pp. 989-1001.

77. Fernández-Mateos, A.; Madrazo, S.E.; Teijón, P.H.; González, R.R. Titanocene-promoted eliminations on epoxy alcohols and epoxy esters. Eur. J. Org. Chem. 2010, 856-861.

78. Fernández-Mateos, A.; Teijón, P.H.; Radical reactions on pinene-oxide derivatives induced by Ti(III). Tetrahedron 2011, 67, 9529-9534.

79. Hardouin, C.; Doris, E.; Rousseau, B.; Mioskowski, C. Concise synthesis of anhydrovinblastine from leurosine. Org. Lett. 2002, 4, 1151-1153.

80. Barrero, A.F.; Quìlez del Moral, J.F.; Sànchez, E.M.; Arteaga, J.F. Regio- and diastereo-selective reductive coupling of vinylepoxides catalyzed by titanocene chloride. Org Lett. 2006, 8, 669-672.

81. Aldegunge, M.J.; Astedo, L.; Granja, J.R. Synthesis of 2-ene-1,4-diols by a new cascade-opening of 1,3-diepoxides: towards an efficient synthesis of dihydroxytaxoid derivatives. Chem. Eur. J. 2009, 15, 4785-4787.

82. Justicia, J; Jimenez, T.; Morcillo, S.P.; Cuerva, J.M.; Oltra, J.E. Mixed disproportionation versus radical trapping in titanocene (III)-promoted epoxide openings. Tetrahedron 2009, 65, 10837-10841.

83. Barrero, A.F.; Rosales, A.; Cuerva, J.M.; Oltra, J.E. Unified synthesis of eudesmanolides, combining biomimetic strategies with homogeneous catalysis and free-radical chemistry. Org. Lett. 2003, 5, 1935-1938.

84. Justicia, J.; Rosales, B.E.; Oller-Lopez, J.L.; Valdivia, N.; Haidour, A.; Oltra, J.E.; Barrero, A.F.; Cardenas, D.J.; Cuerva, J.M. Titanocene-catalyzed cascade cyclization of epoxypolyprenes: Straightforward synthesis of terpenoids by free-radical chemistry. Chem. Eur. 2004, 10, 1778-1788.

85. Justicia, J.; Oltra, J.E.; Cuerva, J.M. Exploiting Pd-II and Ti-III chemistry to obtain gammadioxygenated terpenoids: Synthesis of rostratone and novel approaches to aphidicolin and pyripyropene A. J. Org. Chem. 2005, 70, 8265-8272.

86. Gansäuer, A.; Worgull, D.; Justicia, J. Catalytic epoxypolyene cyclization via radicals: A simple total synthesis of sclareol oxide and its 8-epimer. Synthesis-Stuttgart 2006, 2151-2154. 
87. Justicia, J.; Campanã, G.A.; Bazdi, B.; Robles, R.; Cuerva, J.M.; Oltra, J.E. Titanium-catalyzed enantioselective synthesis of alpha-ambrinol. Adv. Synth. Catal. 2008, 350, 571-576.

88. Gansäuer, A.; Bluhm, H. Reagent-controlled transition-metal-catalyzed radical reactions. Chem. Rev. 2000, 100, 2771-2788.

89. Cuerva, J.M.; Campanã, A.G.; Justicia, J.; Rosales, A.; Oller-Lopez, J.L.; Robles, R.; Cardenas, D.J.; Bunuel, E.; Oltra, J.E. Water: The ideal hydrogen-atom source in free-radical chemistry mediated by Ti-III and other single-electron-transfer metals? Angew. Chem. Int. Ed. 2006, 45, 5522-5526.

90. Paradas, M.; Campaña, A.G.; Marcos, M.L.; Justicia, J.; Haidour, A.; Robles, R.; Cárdenas, D.J.; Oltra, E.J.; Cuerva, J.M. Unprecedented H-atom transfer from water to ketyl radicals mediated by $\mathrm{Cp}_{2}$ TiCl. Dalton Trans. 2010, 39, 8796-8800.

91. Paradas, M.; Campaña, A.G.; Jiménez, T.; Robles, R.; Oltra, J.E.; Buñuel, E.; Justicia, J.; Cárdenas, D.J.; Cuerva, J.M. Understanding the exceptional hydrogen-atom donor characteristics of water in $\mathrm{Ti}^{\mathrm{III}}$ - mediated free-radical chemistry. J. Am. Chem. Soc. 2010, 132, 12748-12756.

92. Jiménez, T.; Campaña, A.G.; Bazdi, B.; Paradas, M.; Arráez-Román, D.; Segura-Carretero, A.; Fernández-Gutiérrez, A.; Oltra, J.E.; Robles, R.; Justicia, J.; Cuerva, J.M. Radical reduction of epoxides using a titanocene (III) water system: synthesis of $\beta$-deuterated alcohols and their use as internal standards in food analysis. Eur. J. Org. Chem. 2010, 4288-4295.

93. Gansäuer, A.; Otte, M.; Shi, L. Radical cyclizations terminated by Ir-catalyzed hydrogen atom transfer. J. Am. Chem. Soc. 2011, 133, 416-417.

94. Gansäuer, A.; Fan, C.A.; Piester, F. Sustainable radical reduction through catalytic hydrogen atom transfer. J. Am. Chem. Soc. 2008, 130, 6916-6917.

95. Gansäuer, A.; Narayan, S. Titanocene-catalysed electron transfer-mediated opening of epoxides. Adv. Synth. Cat. 2002, 344, 465-475.

96. Gansäuer, A.; Bluhm, H.; Lauterbach, T. Titanocene-catalysed enantioselective opening of meso-epoxides. Adv. Synth. Catal. 2001, 343, 785-787.

97. Gansäuer, A.; Bluhm, H.; Rinker, B.; Narayan, S.; Schick, M.; Lauterbach, T.; Pierobon, M. Reagent-controlled stereoselectivity in titanocene-catalyzed epoxide openings: Reductions and intermolecular additions to alpha, beta-unsaturated carbonyl compounds. Chem. Eur. J. 2003, 9, 531-542.

98. Gansäuer, A.; Narayan, S.; Schiffer-Ndene, N.; Bluhm, H.; Oltra, J.E.; Cuerva, J. M.; Rosales, A.; Nieger, M. An improved synthesis of Kagan's menthyl substituted titanocene and zirconocene dichloride, comparison of their crystal structures, and preliminary catalyst evaluation. J. Organomet. Chem. 2006, 691, 2327-2331.

99. Gansäuer, A.; Bluhm, H.; Pierobon, M.; Keller, M. Conformational preferences of titanocene dichlorides with ligands derived from menthol: Comparison of structures in solution and in the crystal. Organometallics 2001, 20, 914-919.

100. Gansäuer, A.; Fan, C.-A.; Keller, F.; Karbaum, P. Regiodivergent epoxide openining: A concept in stereoselective catalysis beyond classical kinetic resolution and desymmetrizations. Chem. Eur. J. 2007, 13, 8084-8090.

101. Gansäuer, A.; Shi, L.; Otte, M. Catalytic enantioselective radical cyclization via regiodivergent epoxide opening. J. Am. Chem. Soc. 2010, 132, 11858-11859. 
102. Gansauer, A.; Fan, C.-A.; Keller, F.; Keil, J. Titanocene-catalyzed regiodivergent epoxide openings. J. Am. Chem. Soc. 2007, 129, 3484-3485.

103. Barrero, A.F.; Rosales, A.; Cuerva, J.M.; Gansäuer, A.; Oltra, J.E. Titanocene-catalyzed, selective reduction of ketones in aqueous media. A safe, mild, inexpensive procedure for the synthesis of secondary alcohols via radical chemistry. Tetrahedron Lett. 2003, 44, 1079-1082.

104. Oller-López, J.L.; Campaña, A.G.; Cuerva, J.M.; Oltra, J.E. Aromatic carbonyl compound reduction and pinacol coupling processes mediated by titanocene(III)/Zn in water. Synthesis 2005, 2619-2622.

105. Chakraborty, T.K.; Das, S. Synthesis of chiral 1,3-diols by radical-mediated regioselective opening of 2,3-epoxy alcohols using Cp(2)TiCl. Tetrahedron Lett. 2002, 43, 2313-2315.

106. Hardouin, C.; Chevallier, F.; Rousseau, B.; Doris, E. Cp $\mathrm{p}_{2}$ TiCl-mediated selective reduction of alpha,beta-epoxy ketones. J. Org. Chem. 2001, 66, 1046-1048.

107. Bermejo, F.; Sandoval, C. $\mathrm{Cp}_{2}$ TiCl-promoted isomerization of trisubstituted epoxides to exomethylene allylic alcohols on carvone derivatives. J. Org. Chem. 2004, 69, 5275-5280.

108. Barrero, A.F.; Cuerva, J.M.; Alvarez-Manzaneda, E.J.; Oltra, J.E.; Chahboun, R. First synthesis of achilleol A using titanium(III) chemistry. Tetrahedron Lett. 2002, 43, 2793-2796.

109. Barrero, A.F.; Cuerva, J.M.; Herrador, M.M.; Valdivia, M.V. A new strategy for the synthesis of cyclic terpenoids based on the radical opening of acyclic epoxypolyenes. J. Org. Chem. 2001, 66, 4074-4078.

110. Barrero, A.F.; Oltra, J.E.; Cuerva, J.M.; Rosales, A. Effects of solvents and water in Ti(III)-mediated radical cyclizations of epoxygermacrolides. Straightforward synthesis and absolute stereochemistry of (+)-3 $\alpha$-hydroxyreynosin and related eudesmanolides. J. Org. Chem. 2002, 67, 2566-2571.

111. Nakai, K.; Kamoshita, M.; Doi, T.; Yamada, H.; Takahashi, T. Stereo- and regio-selective Ti-mediated radical cyclization of epoxy-alkenes: Synthesis of the $\mathrm{A}$ and $\mathrm{C}$ ring synthons of paclitaxel. Tetrahedron Lett. 2001, 42, 7855-7857.

112. Gansäuer, A.; Klatte, M.; Brändle, G.M.; Friedrich, J. Catalytic hydrogen atom transfer (HAT) for sustainable and diastereoselective radical reduction. Angew. Chem. Int. Ed. 2012, 51, 8891-8894.

113. Chakraborty, T.K.; Samanta, R.; Das, S. Radical-mediated opening of 2,3-epoxy alcohols using $\mathrm{Cp}_{2} \mathrm{TiCl}$ : Stereoselective construction of quaternary chiral centers. J. Org. Chem. 2006, 71, 3321-3324.

114. Dötz, K.H.; Gomes da Silva, E. Carbohydrate-modified fused pyranosylidene complexes via radical addition of epoxides to unsaturated metal carbenes. Tetrahedron 2000, 56, 8291-8299.

115. Fernández-Mateos, A.; Martín de la Nava, E.; Pascual Coca, G.; Ramos Silvo, A.; Rubio González, R. Radicals from epoxides. Intramolecular addition to aldehyde and ketone carbonyls. Org. Lett. 1999, 1, 607-609.

116. Fernández-Mateos, A.; Mateos Burón, I.; Rabanedo Clemente, R.; Ramos Silvo, A.I.; Rubio González, R. Radical cyclization of epoxynitriles mediated by titanocene chloride. Synlett 2004, 1011-1014.

117. Gansäuer, A.; Lauterbach, T.; Geich-Gimbel, D. Polarity matching of radical trapping: High yielding 3-exo and 4-exo cyclizations. Chem. Eur. J. 2004, 10, 4983-4990. 
118. Fernández-Mateos, A.; Mateos Burón, L.; Martín de la Nava, E.M.; Rabanedo Clemente, R.; Rubio González, R.; Sanz González, F. Effect of tether length on Ti(III)-mediated cyclization of epoxyalkenes and unsaturated epoxyketones. Synlett 2004, 2553-2557.

119. Friedrich, J.; Dolg, M.; Gansäuer, A.; Geich-Gimbel, D.; Lauterbach, T. A combined theoretical and experimental study of efficient and fast titanocene-catalyzed 3-exo cyclizations. J. Am. Chem. Soc. 2005, 127, 7071-7077.

120. Justicia, J.; de Cienfuegos, L.A.; Campaña, A.G.; Miguel, D.; Jakoby, V.; Gansäuer, A.; Cuerva, J.M. Bioinspired terpene synthesis: a radical approach. Chem. Soc. Rev. 2011, 40, $3525-3537$.

121. Ruano, G.; Grande, M.; Anaya, J.J. Stereospecific synthesis of highly functionalized tricyclic beta-lactams by radical cyclizations using titanocene monochloride. J. Org. Chem. 2002, 67, 8243-8246.

122. Ruano, G.; Matiánez, J.; Grande, M. Stereospecific synthesis of polyfunctionalized carbacephams induced by titanocene(III) chloride. J. Org. Chem. 2003, 68, 2024-2027.

123. Friedrich, J.; Walczak, K.; Dolg, M.; Piestert, F.; Lauterbach, T.; Worgull, D.; Gansäuer, A. Titanocene catalyzed 4-exo cyclizations: Mechanism, experiment, catalyst design. J. Am. Chem. Soc. 2008, 130, 1788-1769.

124. Gansäuer, A.; Worgull, D.; Knebel, K.; Huth, I.; Schnakenburg, G. 4-Exo cyclizations by template catalysis. Angew. Chem. Int. Ed. 2009, 48, 8882-8885.

125. Gansäuer, A.; Greb, A.; Huth, I.; Worgull, D.; Knebel, K. Formal total synthesis of (+/-)-fragranol via template catalyzed 4-exo cyclization. Tetrahedron 2009, 65, 10791-10796.

126. Gansäuer, A.; Knebel, K.; Kube, C.; van Gastel, M.; Cangonul, A.; Daasbjerg, K.; Hangele, T.; Hulsen, M.; Dolg, M.; Friedrich, J. Radical 4-exo cyclization via template catalysis. Chem. Eur. J. 2012, 18, 2591-2599.

127. Ziegler, F.E.; Sarpong, M.A. Radical cyclization studies directed toward the synthesis of BMS-200475 'entecavir': The carbocyclic core. Tetrahedron 2003, 59, 9013-9018.

128. Fernández-Mateos, A.; Herrero Teijón, P.; Rabanes Clemente, R.; Rubio Gonzalez, R. Radical reactions of epoxy esters induced by titanocene chloride. Tetrahedron Lett. 2006, 47, 7755-7758.

129. Leca, D.; Fensterbank, L.; Lacôte, E.; Malacria, M. Titanium-mediated domino radical cyclization/beta elimination of phosphine oxides. Angew Chem. Int. Ed. 2004, 43, 4220-4222.

130. Leca, D.; Song, K.; Albert, M.; Goançalves, M.G.; Fensterbank, L.; Lacôte, E.; Malacria, M. Titanocene-mediated intramolecular radical vinylations. Synthesis 2005, 1405-1420.

131. Gansäuer, A.; Rinker, B.; Pierobon, M.; Grimme, S.; Gerenkamp, M.; Muck-Lichtenfeld, C. A radical tandem reaction with homolytic cleavage of a Ti-O bond. Angew. Chem. Int. Ed. 2003, 42, 3687-3690.

132. Gansäuer, A.; Rinker, B.; Ndene-Schiffer, N.; Pierobon, M.; Grimme, S.; Gerenkamp, M.; Muck-Lichtenfeld, C. A radical roundabout for an unprecedented tandem reaction including a homolytic substitution with a titanium-oxygen bond. Eur. J. Org. Chem. 2004, 2337-2351.

133. Gansäuer, A.; Fleckhaus, A.; Lafont, M.A.; Okkel, A.; Kotsis, K.; Anoop, A.; Neese, F. Catalysis via homolytic substitutions with $\mathrm{C}-\mathrm{O}$ and Ti-O bonds: Oxidative additions and reductive eliminations in single electron steps. J. Am. Chem. Soc. 2009, 131, 16989-16999. 
134. Apte, S.; Radetich, B.; Shin, S.; RajanBabu, T.V. Silylstannylation of highly functionalized acetylenes. Synthesis of precursors for annulations via radical or Heck reactions. Org. Lett. 2004, 6, 4053-4056.

135. Gansäuer, A.; Pierobon, M.; Bluhm, H. Stereoselective synthesis of tri- and tetrasubstituted olefins by tandem cyclization addition reactions featuring vinyl radicals. Angew. Chem. Int. Ed. 2002, 41, 3206-3208.

136. Trost, B.M.; Shen, H.C.; Surivet, J.P. An enantioselective biomimetic total synthesis of (-)-siccanin. Angew. Chem. Int. Ed. 2003, 42, 3943-3947.

137. Trost, B.M.; Shen, H.C.; Surivet, J.P. Biomimetic enantioselective total synthesis of (-)-siccanin via the Pd-catalyzed asymmetric allylic alkylation (AAA) and sequential radical cyclizations. J. Am. Chem. Soc. 2004, 126, 12565-12579.

138. Haruo, Y.; Hasegawa, T.; Tanaka, H.; Takahashi, T. Total synthesis of (+/-)-smenospondiol by titanium(III)-mediated tandem radical cyclization. Synlett 2001, 1935-1937.

139. Arteaga, J.F.; Diéguez, H.R.; González-Delgado, J.A.; Quílez del Moral, J.F.; Barrero, A.F. Control of the regio- and diastereoselectivity for the preparation of highly functionalized terpenic cyclopentanes through radical cyclization. Eur. J. Org. Chem. 2011, 5002-5011.

140. Saha, S.; Roy, S.C. Titanocene (III) chloride mediated radical induced synthesis of (-)-methylenolactocin and (-)-protolichesterinic acid. Tetrahedron 2010, 66, 4278-4283.

141. Fernández-Mateos, A.; Ramos Silvo, A.I.; González, R.R.; Simmonds, M.S.J. Synthesis of CDE molecular fragments related to sendanin mediated by titanocene(III). Org. Biomol. Chem. 2012, $10,5620-5628$.

142. Cuerva, J.M.; Justicia, J.; Oller-López, J.L.; Bazdi, B.; Oltra, J.E. The growing impact of titanocene(III)-mediated radical epoxide opening on the synthesis of natural products. Mini-Rev. Org. Chem. 2006, 3, 23-35.

143. Gansäuer, A.; Justicia, J.; Rosales, A.; Worgull, D.; Rinker, B.; Cuerva, J.M.; Oltra, J.E. Transition-metal-catalyzed allylic substitution and titanocene-catalyzed epoxypolyene cyclization as a powerful tool for the preparation of terpenoids. Eur. J. Org. Chem. 2006, 4115-4127.

144. Yamaoka, M.; Fukatsu, Y.; Nakazaki, A.; Kobayashi, S. Synthetic study of fomitellic acids: Construction of the AB ring moiety. Tetrahedron Lett. 2009, 50, 3849-3852.

145. Justicia, J.; Oller-López, J.L.; Campaña, A.G.; Oltra, J.E.; Cuerva, J.M.; Buñuel, E.; Cárdenas, D.J. 7-Endo radical cyclizations catalyzed by titanocene (III). Straightforward synthesis of terpenoids with seven-membered carbocycles. J. Am. Chem. Soc. 2005, 127, 14911-14921.

146. Mandal, S.K.; Roy, S.C. Titanocene(III) mediated 8-endo radical cyclizations for the synthesis of eight-membered cyclic ethers. Tetrahedron Lett. 2006, 47, 1599-1601.

147. di Lena, F.; Matyjaszewski, K. Transition metal catalysts for controlled radical polymerization. Prog. Polym. Sci. 2010, 35, 959-1021.

148. Nomura, K. New approaches in precise synthesis of polyolefins containing polar functionalities by olefin copolymerizations using transition metal catalysis. J. Synth. Org. Chem. Jpn. 2012, 68, 1150-1158.

149. Kwark, Y.-J.; Kim, J.; Novak, B.M. Titanium complexes: A possible catalyst for controlled radical polymerization. Macromol. Res. 2007, 15, 31-38. 
150. Bhattacharjee, M.; Patra, B.N. $\left[\mathrm{CP}_{2} \mathrm{TiCl}_{2}\right]$ catalyzed polymerization in water: polymerization of methylmethacrylate to a high molecular weight polymer. Polymer 2004, 45, 3111-3114.

151. Asandei, A.D.; Moran, I.W. TiCp $\mathrm{p}_{2} \mathrm{Cl}$-catalyzed living radical polymerization of styrene initiated by oxirane radical ring opening. J. Am. Chem. Soc. 2004, 126, 15932-15933.

152. Ma, L.; Liu, W.; Sheng, Y.; Huang, Q.; Yang, W. Synthesis of well-defined star-shaped organosiloxane-functionalized polymethylmethacrylate promoted by epoxide-derived titanocene alkoxides via radical polymerization. J. Appl. Polym. Sci. 2011, 12, 1652-1658.

153. Asandei, A.D.; Saha, G. Living ring-opening polymerization of cyclic esters with epoxide-derived titanium alkoxides. Macromol. Rapid. Commun. 2005, 26, 626-631.

154. Asandei, A.D.; Simpson, C.P.; Yu, H.S. $\mathrm{Cp}_{2}$ TiCl-catalyzed controlled radical polymerization of isoprene initiated from epoxides, aldehydes and halides. Polym. Prepr. Am. Chem. Soc. 2008, 49, 73-74.

155. Asandei, A.D.; Simpson, C.P. Cp 2 TiCl-catalyzed synthesis of styrene/isoprene copolymers by controlled radical polymerization. Polym. Prepr. Am. Chem. Soc. 2008, 49, 75-76.

156. Asandei, A.D.; Moran, I.W. The ligand effect in Ti-mediated living radical styrene polymerizations initiated by epoxide radical ring opening. I. Alkoxide and bisketonate Ti complexes. J. Polym. Sci. Part A Polym. Chem. 2005, 43, 6028-6038.

157. Asandei, A.D.; Moran, I.W. The ligand effect in Ti-mediated living radical styrene polymerizations initiated by epoxide radical ring opening. II. Scorpionate and half-sandwich LTiCl 3 complexes. J. Polym. Sci. Part A Polym. Chem. 2005, 43, 6039-6047.

158. Asandei, A.D.; Moran, I.W. The ligand effect in Ti-mediated living radical styrene polymerizations initiated by epoxide radical ring opening. III. Substituted sandwich metallocenes. J. Polym. Sci. Part A Polym. Chem. 2006, 44, 1060-1070.

159. Asandei, A.D.; Moran, I.W.; Saha, G.; Chen, Y. Titanium-mediated living radical styrene polymerizations. V. $\mathrm{Cp}_{2}$ TiCl-catalyzed initiation by epoxide radical ring opening: Effect of solvents and additives. J. Polym. Sci. Part A Polym. Chem. 2006, 44, 2015-2026.

160. Asandei, A.D.; Moran, I.W.; Saha, G.; Chen, Y. Titanium-mediated living radical styrene polymerizations. VI. $\mathrm{Cp}_{2}$ TiCl-catalyzed initiation by epoxide radical ring opening: effect of the reducing agents, temperature, and titanium/epoxide and titanium/zinc ratios. J. Polym. Sci. Part A Polym. Chem. 2006, 44, 2156-2165.

161. Asandei, A.D.; Chen, Y. $\mathrm{Cp}_{2}$ TiCl-catalyzed set reduction of aldehydes: A new initiating protocol for living radical polymerization. Macromolecules 2006, 39, 7549-7554.

162. Asandei, A.D.; Chen, Y.; Adebolu, O.I.; Simpson, C.P. Living ring-opening polymerization of E-caprolactone with $\mathrm{Ti}$ alkoxides derived from the $\mathrm{Cp}_{2} \mathrm{TiCl}$-catalyzed SET reduction of aldehydes. J. Polym. Sci. Part A Polym. Chem. 2008, 46, 2869-2877.

163. Tehfe, M.A.; Lalevèe, J.; Morlet-Savary, F.; Graff, B.; Fouassier, J.P. On the use of bis(cyclopentadienyl)titanium(IV) dichloride in visible-light-induced ring-opening photopolymerization. Macromolecules 2012, 45, 356-361.

(C) 2012 by the authors; licensee MDPI, Basel, Switzerland. This article is an open access article distributed under the terms and conditions of the Creative Commons Attribution license (http://creativecommons.org/licenses/by/3.0/). 